ARTICLE

DOI: $10.1038 / \mathrm{s} 41467-017-01181-4$

\title{
Phosphatidylinositol transfer protein- $\alpha$ in platelets is inconsequential for thrombosis yet is utilized for tumor metastasis
}

Liang Zhao ${ }^{1}$, Chelsea L. Thorsheim¹, Aae Suzuki ${ }^{1}$, Timothy J. Stalker (1) 1, Sang H. Min', Lurong Lian', Gregory D. Fairn (10) ${ }^{2}$, Shamshad Cockcroft (10 ${ }^{3}$, Amy Durham ${ }^{4}$, Sriram Krishnaswamy ${ }^{5} \&$ Charles S. Abrams A $^{1,6}$

Platelets are increasingly recognized for their contributions to tumor metastasis. Here, we show that the phosphoinositide signaling modulated by phosphatidylinositol transfer protein type $\alpha(P I T P \alpha)$, a protein which shuttles phosphatidylinositol between organelles, is essential for platelet-mediated tumor metastasis. PITP $\alpha$-deficient platelets have reduced intracellular pools of phosphoinositides and an $80 \%$ reduction in $\mathrm{IP}_{3}$ generation upon platelet activation. Unexpectedly, mice lacking platelet PITP $\alpha$ form thrombi normally at sites of intravascular injuries. However, following intravenous injection of tumor cells, mice lacking PITP $\alpha$ develop fewer lung metastases due to a reduction of fibrin formation surrounding the tumor cells, rendering the metastases susceptible to mucosal immunity. These findings demonstrate that platelet PITP $\alpha$-mediated phosphoinositide signaling is inconsequential for in vivo hemostasis, yet is critical for in vivo dissemination. Moreover, this demonstrates that signaling pathways within platelets may be segregated into pathways that are essential for thrombosis formation and pathways that are important for non-hemostatic functions.

\footnotetext{
${ }^{1}$ Department of Medicine, School of Medicine, University of Pennsylvania, Philadelphia, PA 19104, USA. ${ }^{2}$ St. Michael's Hospital, Toronto, ON, Canada M5B 1W8. ${ }^{3}$ Division of Bioscience, University College London, London WC1E 6BT, UK. ${ }^{4}$ School of Veterinary Medicine, University of Pennsylvania, Philadelphia, PA 19104, USA. ${ }^{5}$ Children's Hospital of Philadelphia, Philadelphia, PA 19104, USA. ${ }^{6}$ Department of Pathology, School of Medicine, University of Pennsylvania, Philadelphia, PA 19104, USA. Correspondence and requests for materials should be addressed to C.S.A. (email: abrams@upenn.edu)
} 
P latelets are best known for their contribution to hemostasis, but several lines of evidence indicate that they also contribute to tumor metastasis. For example, elevated platelet counts are associated with a poor prognosis in patients with cancer, whereas low platelet counts are associated with reduced metastatic burden ${ }^{1-6}$. Additionally, studies suggest that platelets assist tumor cell adhesion to the vasculature and enhance tumor cell growth. Aberrant platelet activation and aggregation are frequently found in the vasculature of cancer patients, especially in patients with metastatic tumors ${ }^{7-10}$. Furthermore, studies that use genetically engineered mice with altered platelet functions, or those that use pharmacologic inhibitors against platelet activation, show that platelets can protect circulating tumor cells from elimination by the immune system and therefore support further metastasis ${ }^{11,12}$.

Platelet-mediated vascular plug formation is critically dependent on phosphatidylinositol signaling, although it only comprises about $8 \%$ of the phospholipids contained in a typical mammalian cell ${ }^{13-17}$. The phosphatidylinositol head group is capable of being differentially phosphorylated, generating a family of seven functionally distinct phospholipids, called phosphoinositides (PtdIns) ${ }^{13}$. Intracellular PtdIns concentrations are tightly regulated both in time and space, and the distribution between the various PtdIns species changes within seconds after agonist stimulation. PtdIns generation is a key cellular event in all eukaryotic cells, including in platelets, where it regulates integrin activation, actin assembly, and secretion ${ }^{13,}{ }^{14}$. However, whether platelet PtdIns signaling contributes to platelet-mediated tumor metastasis is unknown.

Since PtdIns contain hydrophobic acyl side chains that render them insoluble in the aqueous cytoplasm, they are assumed to always be associated within a lipid bilayer. Curiously, the sites of synthesis of different PtdIns are on the surfaces of distinct cellular organelles. For example, phosphatidylinositol is synthesized in the endoplasmic reticulum (ER), while PtdIns(4)P is synthesized on the surface of internal granules, such as on endosomes, and $\operatorname{PtdIns}(4,5) \mathrm{P}_{2}$ is synthesized on the cell membrane ${ }^{18,19}$. This implies that the sequential synthesis of polyphosphorylated phosphatidylinositols, such as $\operatorname{PtdIns}(4,5) \mathrm{P}_{2}$, begins with a

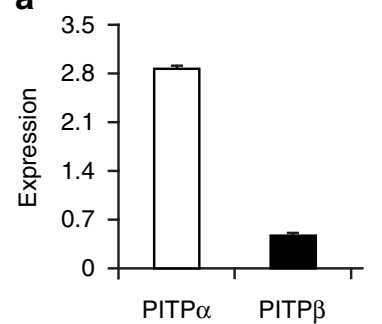

C

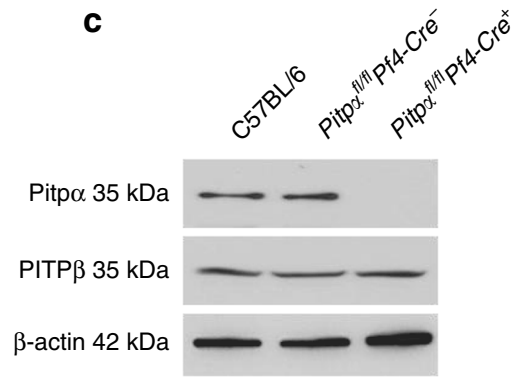

b

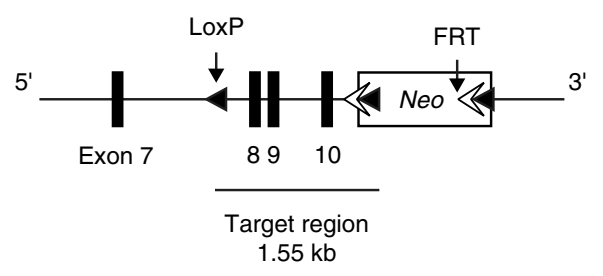

d

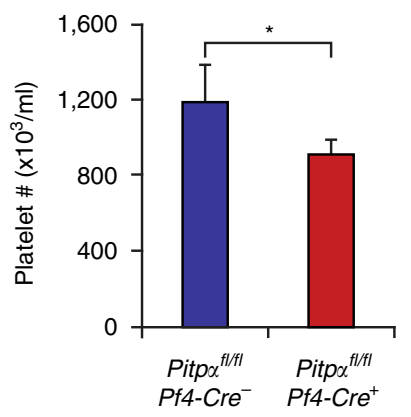

f

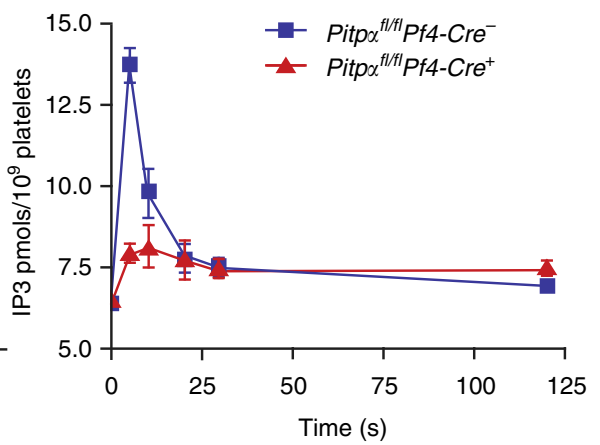

Fig. 1 PITP $\alpha$ mediates Ptdlns synthesis and IP 3 production in mouse platelets. a Quantification of immunoblot demonstrates the types of class I PITP expressed in platelet lysates using isoform-specific antibodies. Shown is the relative abundance of individual PITP isoforms in platelets from wild-type mice when normalized to recombinant PITP protein standards ( $n=3$ mice per group; error bars are standard deviation (s.d.)). $\mathbf{b}$ Schematic representation of the conditional targeting strategy. Exons 8, 9, and 10 were targeted by the insertion of loxP recombination sites to generate Pitp $\alpha$ floxed alleles $\left(P i t p \alpha^{f l / f l}\right)$. c Immunoblot of platelet lysate demonstrating the specific deletion of the PITP $\alpha$ isoform in Pitp $\alpha^{f l / f l} P f 4-C r e^{+}$platelets. $\mathbf{d}$ CBC analyses show decreased platelet count in Pitpo ${ }^{f l / f l} P f 4-C r e^{+}$mice compared to their littermate controls ( $n=3$ mice per group; error bars are s.d.; ${ }^{*} p<0.05$, unpaired Student's $t$-test). e Ptdlns synthesis in thrombin-stimulated platelets derived from Pitp $\alpha^{f l / f l} P f 4-C r e^{-}$and Pitp $\alpha^{f l / f l} P f 4-C r e^{+}$mice. Pooled analysis of experiments shows the effect of the loss of PITP $\alpha$ on Ptdlns(4)P and Ptdlns $(4,5) P_{2}$ generation following thrombin stimulation at $1 \mathrm{U} / \mathrm{ml}(n=3$ mice per group; error bars are s.d.; ${ }^{\star} p<0.05$, unpaired Student's $t$-test). $\mathbf{f}$ The effect on $\mathrm{IP}_{3}$ production by the loss of PITP $\alpha$ was analyzed. IP 3 production was impaired even at the earliest analyzed time point ( $n=3$ mice per group; error bars are s.d.) 
phosphatidylinositol production in the ER, and the intermediate isoforms are trafficked between the organelles before final production in the plasma membrane. We and others have shown that the sequential enzymatic steps required for higher-order phosphoinositide synthesis occur within seconds $14,20,21$. Consequently, a mechanism for rapidly transferring phosphatidylinositol between membranes is required.

Phosphatidylinositol transfer proteins (PITP) facilitate the transfer of insoluble phosphatidylinositol from one membrane to another in vitro. They achieve this by binding and encompassing the fatty acid side chains of phospholipids and transporting the phospholipids throughout the cytoplasm. Mammalian cells contain both PITP $\alpha$ and PITP $\beta$ isoforms, which are small, highly conserved, and ubiquitously expressed single PITP domain soluble proteins. Ablation or knock down of PITP $\alpha$ impairs viability, membrane trafficking, and cytokinesis ${ }^{22-25}$. Because the phosphatidylinositol transfer activity of PITP $\alpha$ is required for the synthesis of phosphoinositides and for the regulation of Ptdins kinases, it has been assumed that PITP $\alpha$ is essential for all of the signaling events that utilize phosphoinositides, including platelets $^{26,27}$.

In this study, we investigate whether platelet-specific disruption of phosphatidylinositol metabolism mediated by PITP $\alpha$ impacts hemostatic and non-hemostatic functions of platelets in tumor dissemination. Our study unexpectedly shows that PITP $\alpha$, the major PITP isoform in murine platelets, is inconsequential for hemostasis in vivo. However, $\operatorname{PITP} \alpha$-mediated $\operatorname{PtdIns}(4,5) \mathrm{P}_{2}$ synthesis and $\mathrm{IP}_{3}$ production in platelets are critical to promote platelet-mediated lung metastasis of intravenous injected tumor cells. We demonstrate that signaling pathways required for thrombosis formation may be independent from those pathways required for non-hemostatic platelet functions, such as those pathways that regulate interactions with immune cells.

\section{Results}

Conditional deletion of the PITP $\alpha$ in murine platelets. Platelets, like other mammalian cells, contain both the PITP $\alpha$ and PITP $\beta$ isoforms. We observed that the PITP $\alpha$ isoform is approximately six-fold more abundant than PITP $\beta$ in murine platelets (Fig. 1a and Supplementary Fig. 1). To determine the role of PITP $\alpha$ in platelets, we genetically deleted PITP $\alpha$ from murine platelets and megakaryocytes (Fig. 1b). To accomplish this, the PITP $\alpha$ gene was conditionally targeted at the domain previously demonstrated to be essential for the phosphatidylinositol transfer function of PITP $\alpha^{22,28}$, and the resultant mice were crossed with transgenic mice expressing the CRE recombinase, whose expression was controlled by the megakaryocytespecific platelet-factor-4 promoter $(\mathrm{Pf} 4-\mathrm{Cre})^{29}$. We found no detectable full-length or truncated forms of PITP $\alpha$ protein in the lysates of platelets derived from Pf4-Cre-positive PITP $\alpha$ floxed mice (Pitpo ${ }^{f l f l} P f 4-C r e^{+}$) by immunoblotting. The PITP $\beta$ protein expression remained unchanged in the Pitpo ${ }^{\text {fl/fl }} \mathrm{Pf4}-\mathrm{Cr}{ }^{+}$ mice, with similar expression levels to those in the control Pitpo ${ }^{f l / f l}$ Pf4-Cre $e^{-}$mice (Fig. 1c).

The Pitpo ${ }^{f l / f l} \mathrm{Pf4}-\mathrm{Cr} e^{+}$mice were grossly normal, with body weight, organ morphology, leukocyte counts, and hemoglobin levels that were indistinguishable from the littermate controls (Pitpo ${ }^{f l / f l} \mathrm{Pf4}$-Cre $e^{-}$mice) (Supplementary Fig. 2). Although there was a $15 \%$ decrease in platelet counts in the Pitpo $\alpha^{f l / f l} P f 4-C r e^{+}$ mice (Fig. 1d), it is still within normal range. The mice grew to adulthood without any observable increase in spontaneous hemorrhage, thrombosis, or mortality.

PITPo is essential for platelet phosphoinositide signaling. To study the role of PITP $\alpha$ in the synthesis of phosphoinositides in platelets, we analyzed the concentration of specific phosphoinositides within platelets from Pitpo ${ }^{f l / f l} \mathrm{Pf} 4-\mathrm{Cr} e^{+}$mice by using thinlayer chromatography (TLC). These platelets had a $34.7 \%$ reduction of PtdIns(4)P and a $41.2 \%$ reduction in $\operatorname{PtdIns}(4,5) \mathrm{P}_{2}$ at resting conditions (Fig. 1e). When stimulated with thrombin, the deficiency remained in PITP $\alpha$-null platelets $(30.5 \%$ reduction of PtdIns(4)P levels and 34.1\% reduction of PtdIns(4,5) $\mathrm{P}_{2}$ levels), demonstrating that PITP $\alpha$ is required for the synthesis of higherorder phosphoinositides in platelets.

Following thrombin stimulation, $\operatorname{PtdIns}(4,5) \mathrm{P}_{2}$ in platelets is hydrolyzed by phospholipase $\mathrm{C}$ to generate second messengers, such as $\mathrm{IP}_{3}$. We analyzed $\mathrm{IP}_{3}$ synthesis in thrombin-stimulated platelets that lack PITP $\alpha$, in order to test whether phosphoinositide transfer is required for rapid $\mathrm{IP}_{3}$ production. Although the baseline $\mathrm{IP}_{3}$ level in platelets derived from Pitpo ${ }^{f l / f l} \mathrm{Pf} 4-\mathrm{Cr} \mathrm{e}^{+}$mice was not different from the control mice, the $\mathrm{IP}_{3}$ generation following thrombin stimulation was blunted by approximately $80 \%$, an effect that was apparent as early as $5 \mathrm{~s}$ after agonist stimulation (Fig. 1f). Furthermore, the intracellular calcium levels were lower in $\mathrm{Pitpo}^{f l / f l} \mathrm{Pf4}-\mathrm{Cr} \mathrm{e}^{+}$platelets following thrombin stimulation (Supplementary Fig. 3). These data indicate that PITP $\alpha$-mediated synthesis of PtdIns $(4,5) \mathrm{P}_{2}$ contributes to $\mathrm{IP}_{3}$ formation, which occurs within seconds after agonist stimulation. It is noteworthy that although PITP $\alpha$ is only required for the synthesis of approximately $40 \%$ of platelet $\operatorname{PtdIns}(4,5) \mathrm{P}_{2}$ (Fig. 1e), it is required for a much larger percentage of the $\mathrm{IP}_{3}$ that is synthesized after agonist stimulation (Fig. 1f). Since $\mathrm{IP}_{3}$ is derived entirely from PtdIns $(4,5) \mathrm{P}_{2}$, these results suggest that PITP $\alpha$ may be required for the production of the specific pool of PtdIns $(4,5)$ $\mathrm{P}_{2}$ that is utilized for $\mathrm{IP}_{3}$ formation.

PITPa is inconsequential for platelet aggregation. To determine whether the deletion of PITP $\alpha$ impacts platelet function, we compared the ex vivo aggregation of PITP $\alpha$-null platelets with those of the littermate controls using light transmission aggregometry. PITP $\alpha$-null platelets aggregated normally in response to the platelet agonists that include thrombin, collagen, ADP, PMA, and U46619, at all dosages tested (Fig. 2a and Supplementary Table 1). Ex vivo platelet $\alpha \operatorname{IIb} \beta 3$ integrin activation (JON/A) and secretion (P-selectin) measured by flow cytometry were also normal (Supplementary Table 2). These results were unexpected given the defects in phosphoinositide synthesis and second messenger formation observed in PITP $\alpha$-null platelets.

To determine whether these results also pertained to platelet function in vivo, we investigated whether platelets lacking PITP $\alpha$ formed thrombi normally by using three established murine models. First, we analyzed whether the loss of PITP $\alpha$ in platelets affected tail bleeding times. By analyzing a large number of animals (90 Pitpo flffl Pf4-Cre $e^{+}$mice and 40 Pitpo $^{\text {fl/fl }}$ Pf4-Cre ${ }^{-}$ mice), we could demonstrate that the bleeding time was longer in the Pitpo $\alpha^{f l f l} \mathrm{Pf}_{4}-\mathrm{Cre}^{+}$mice (median time $58.5 \mathrm{~s}$ ) when compared with the Pitpo ${ }^{f l / f l} P f 4-\mathrm{Cre}^{-}$mice (median time $=29.0$ $\mathrm{s}, p<0.005$, unpaired Student's t-test; Fig. 2b). However, the average blood volume lost was comparable between the Pitpo ${ }^{f l}$ ${ }^{f l} \mathrm{Pf4}-\mathrm{Cr} e^{+}$and Pitpo ${ }^{f l / f l} \mathrm{Pf} 4-\mathrm{Cr} e^{-}$mice (Supplementary Fig. 4). Since the absolute differences in bleeding time were small, there was a large amount of variability in this assay even within mice of the same genotype, and the results may be influenced by plateletindependent factors such as coagulation and vascular muscle tone, we analyzed the ability of these mice to form intravascular thrombi using several alternative methods.

Platelet-mediated in vivo thrombosis were directly tested using a $\mathrm{FeCl}_{3}$ carotid injury model by analyzing thrombus formation in response to a chemical injury. Using this method, we could not identify any difference in the rate of thrombus formation between 
a

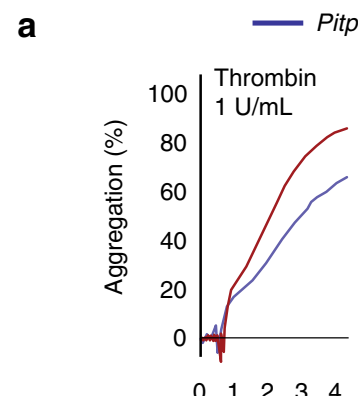

${ }_{i t p} \alpha^{f l / f l} P f 4-C r e^{-}$

- Pitpo ${ }^{f l / f l}$ Pf4-Cre
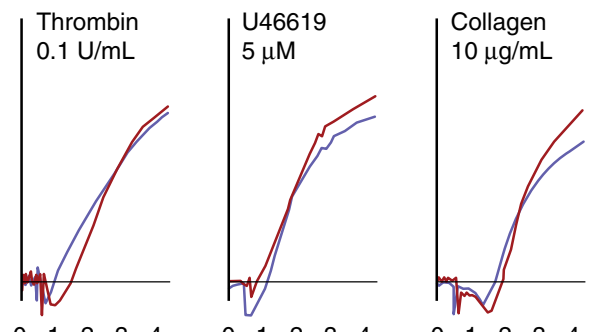

Time (min)
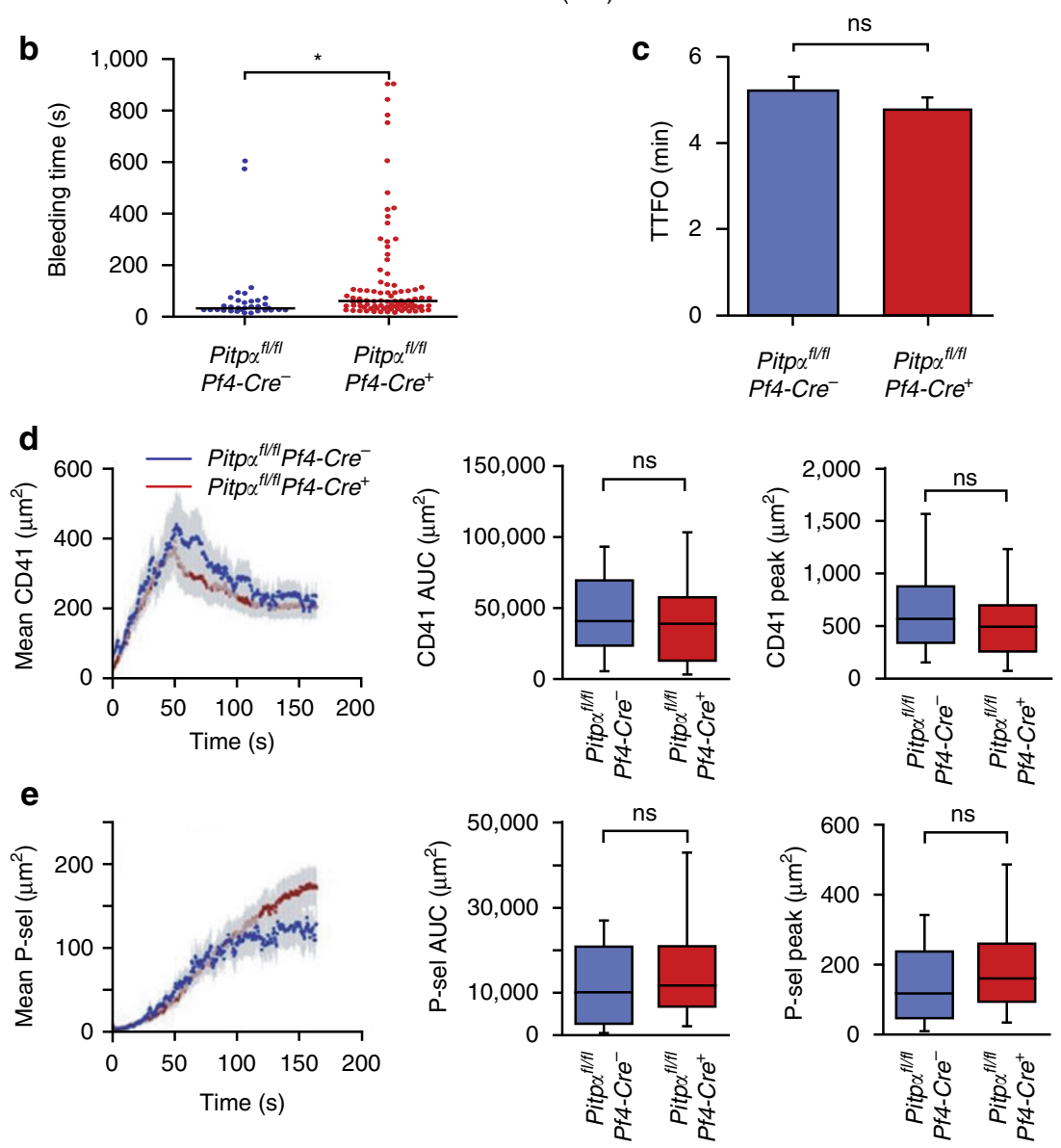

Fig. 2 Platelet PITP $\alpha$ is inconsequential for hemostasis. a Platelets lacking PITP $\alpha$ were analyzed after agonist stimulation in a Lumi-Dual aggregometer. Platelets derived from Pitp $\alpha$ knockout mice exhibited essentially no defect in aggregation in response to all analyzed agonists. $\mathbf{b}$ Tail bleeding times in mice lacking PITP $\alpha$. Pitp $\alpha^{f l / f l} P f 4-C r e^{+}$mice $(n=90)$ and Pitp $\alpha^{f / / f l} P f 4-C r e^{-}$mice $(n=40)$ were analyzed for the duration of their tail bleeding. The median difference was $29.5 \mathrm{~s}$ ( ${ }^{\star} p<0.005$, unpaired Student's t-test). c Carotid arteries of Pitp ${ }^{f / / f l} P f 4-C r e^{+}$mice $(n=5)$ and Pitpo ${ }^{f / / f l} P f 4-C r e^{-}$mice $(n=7)$ were subjected to a ferric chloride induced injury, and blood flow was monitored as a measure of thrombus formation. The time-to-form occlusions (TTFO) of the blood flow were not found to be significantly different between mice lacking PITP $\alpha$ in their platelets and the control mice. Statistical analysis was performed using an unpaired Student's t-test. Error bars are s.d. (d, e). Laser-induced injury model demonstrates normal in vivo thrombosis and platelet secretion in Pitpofl/flPf4-Cre ${ }^{+}$mice. Shown is platelet accumulation (d) and P-selectin exposure (e) in response to a laser-induced injury to mouse cremaster arterioles. The area under the area/time curve and peak area are shown. The graphs show the means for $n=15$ injuries in three Pitpo ${ }^{f / / f l} P f 4-C r e^{-}$mice and $n=25$ injuries in three Pitpo ${ }^{f / / f l} P f 4-C r e^{+}$mice. Statistical analysis was performed using an unpaired Student's $t$-test. Shown are the means \pm s.d. for all figure panels

Pitpo ${ }^{f l / f l} \mathrm{Pf4}-\mathrm{Cr} \mathrm{e}^{+}$mice and Pitpo ${ }^{f l / f l} \mathrm{Pf4}-\mathrm{Cr} \mathrm{e}^{-}$mice (Fig. 2c). We also analyzed thrombosis formation and platelet $\alpha$-granule secretion in response to a laser-induced vascular injury ${ }^{30}$. As shown in Fig. 2d, the loss of platelet PITP $\alpha$ did not significantly decrease platelet accumulation at the injured vessel wall. Similarly, PITP $\alpha$-null platelets translocated normal amounts of P-selectin onto their surface (Fig. 2e), indicating that these genetically modified platelets have no obvious defect in $\alpha$-granule secretion in vivo, confirming the previous ex vivo secretion data.
Taken together, our studies demonstrate that the predominant platelet PITP isoform, PITP $\alpha$, does not contribute significantly to platelet-mediated hemostasis ex vivo or in vivo.

Platelet PITP $\alpha$ is essential for melanoma cell metastasis. In addition to hemostasis, platelets have been implicated in other processes, such as the formation of tumor metastases ${ }^{31}$. To determine whether PITP $\alpha$-mediated phosphoinositide 
a

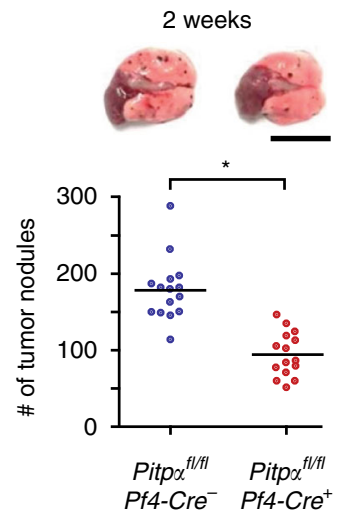

C

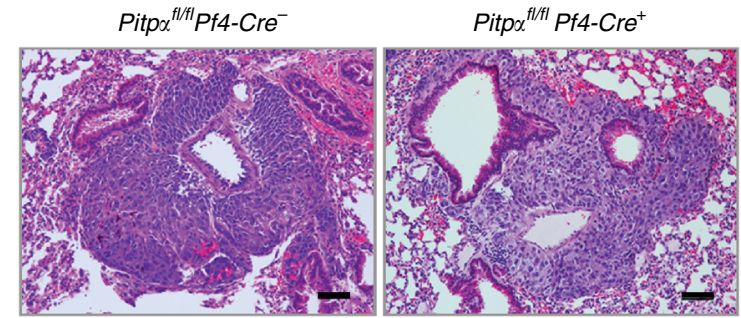

e

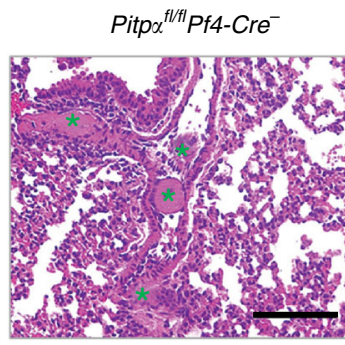

g

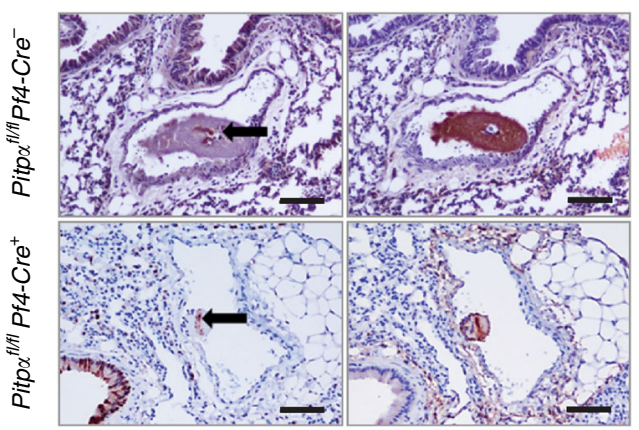

b
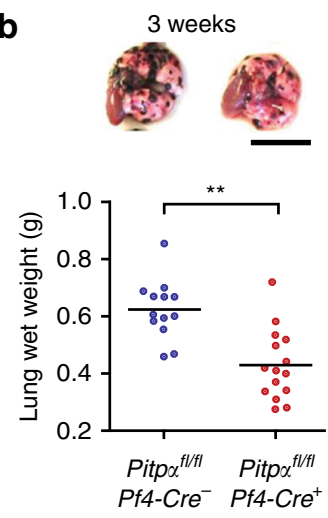

d

f
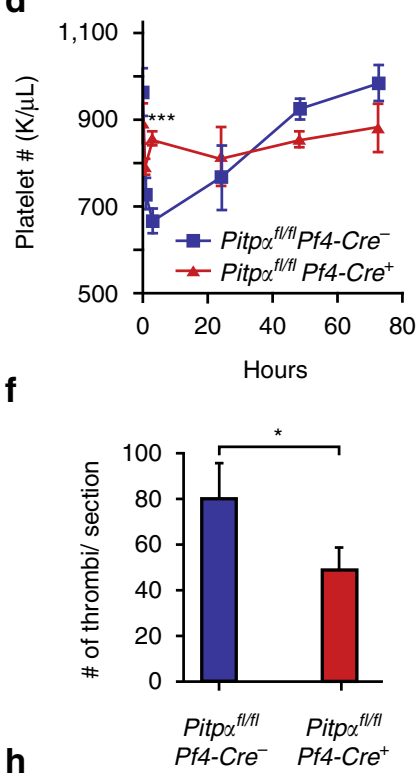

h

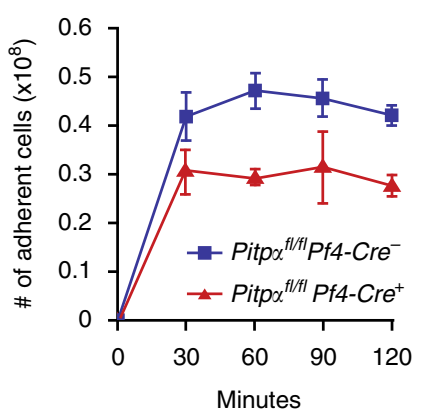

Fig. 3 Loss of PITP $\alpha$ in platelets impairs tumor metastasis formation. a The lungs derived from Pitpa $\alpha^{f / f f l} P f 4-C_{r}{ }^{-}$and Pitpafl/flPf4-Cre ${ }^{+}$mice harvested 2 weeks after tail vein injection with B16F10 melanoma cells. Shown are representative lungs. The number of tumor nodules on the lung surface was reduced in Pitp $\alpha^{f / f f l} P f 4-\mathrm{Cre}^{+}$mice when compared with Pitpa ${ }^{f / / f l} P f 4-\mathrm{Cre}^{-}$controls. Scale bar is $10 \mathrm{~mm}$. ${ }^{*} p<0.0001$, unpaired Student's $t$-test. b Similarly, 3 weeks after tumor injection, the lungs of the Pitpo ${ }^{f / / f / P f 4-C r e}{ }^{+}$mice contained less metastasis than the Pitpo ${ }^{f / / f} P f 4$-Cre ${ }^{-}$mice as indicated by their weights. Scale bar is $10 \mathrm{~mm} .{ }^{* *} p<0.0001$, unpaired Student's $t$-test. $\mathbf{c}$ H\&E staining of tumors in lung tissue sections at 3 weeks after tumor injection show no significant fibrosis or hemorrhage. Black scale bars represent $100 \mu \mathrm{m}$. d Shown are serial platelet counts analyzed after tumor injection. Control mice

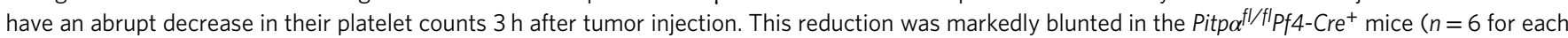
genotype, ${ }^{* \star \star} p<0.05$, unpaired Student's $t$-test). Shown are the means \pm s.d. e H\&E staining for lung tissues at $3 \mathrm{~h}$ after tumor cell injection demonstrated tumor-induced thrombi formation within lung tissue. The stars indicate the tumor-induced thrombi. Black scale bars represent $200 \mu \mathrm{m}$. $\mathbf{f}$ Quantification of CD41-positive thrombi formation observed within lung tissue of the Pitpo ${ }^{f / f f l} P f 4-C r e^{+}$mice $(n=4)$ and the Pitpo $\alpha^{f / f f} P f 4-C r e^{-}$control mice $(n=5)$.

${ }^{\star \star \star} p=0.02$, unpaired Student's $t$-test. Error bars are s.d. $\mathbf{g}$ Immunohistochemistry analysis of tumor-induced thrombi in lung tissues at $3 \mathrm{~h}$ after tumor injection staining for CD41 (platelet marker) and TRP1 (B16F10 tumor cells). The arrows indicate the tumor cells. This demonstrates that the tumor cells are

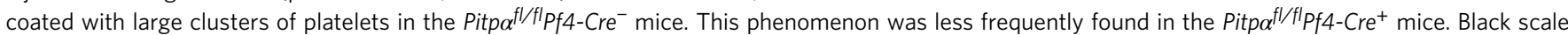
bars represent $100 \mu \mathrm{m}$. h Ex vivo adhesions of platelets on tumor cell layers indicate impaired interactions between Pitpa ${ }^{f / / f l} \mathrm{Pf} 4-\mathrm{Cre} \mathrm{C}^{+}$platelets and tumor cells. $N=3$ mice per group. Shown are the mean \pm s.d. for all figure panels 
metabolism in platelets is involved in tumor dissemination, we utilized a well-characterized B16F10 melanoma model of tumor metastasis $^{32}$. In this model, the quantity of tumor foci were measured following intravenous injection of B16F10 melanoma cells in mice. Two weeks after tumor cell injection, Pitpo ${ }^{f l f l} P f 4$ $\mathrm{Cre}^{+}$mice developed 50\% fewer tumor foci on the surface of their lungs as compared to the littermate controls $(p<0.0001$, unpaired Student's $t$-test; Fig. 3a). Furthermore, 3 weeks after tumor cell injection, the lung weights of freshly dissected Pitpo ${ }^{f l f l} \mathrm{Pf4}-\mathrm{Cre}^{+}$mice were $50 \%$ lower than those harvested from Pitpo ${ }^{f l / f l}$ Pf4-Cre $e^{-}$mice $(p<0.0001$, unpaired Student's $t$-test; Fig. 3b). The histology showed that compared to the Pitpo ${ }^{f l f l}$ Pf4-Cre ${ }^{+}$mice, Pitpo ${ }^{f l / f l}$ Pf4-Cre ${ }^{-}$mice did not develop more hemorrhages or fibrosis in their lungs at 3 weeks after tumor injection (Fig. 3c). This suggested that the increased lung weight in the control mice is due to the metastatic burden of the tumors. Thus, these data indicate that platelet PITP $\alpha$ contributes to the dissemination of intravenous injected B16F10 melanoma cells.

To determine whether this observation was limited to B16F10 melanoma cells, Lewis lung carcinoma (LLC) cells also were injected intravenously, and metastasis formation was evaluated at 2 weeks after tumor injection by counting the number of tumor foci on the lung surface (Supplementary Fig. 5). Again, Pitpo fl ${ }^{f l} \mathrm{Pf4}-\mathrm{Cr} \mathrm{e}^{+}$mice developed significantly less lung metastasis when compared to their littermate controls, demonstrating that the relationship between $\mathrm{Pitp}^{f l / f l} \mathrm{Pf} 4-\mathrm{Cr} e^{+}$platelets and metastasis formation is not unique to a specific tumor cell line.

One possible mechanism by which platelet PITP $\alpha$ contributes to the dissemination of tumor cells was revealed as control mice, but not Pitpo $\alpha^{f l f l} P f 4-C r e^{+}$mice, quickly become thrombocytopenic just $3 \mathrm{~h}$ after injecting the tumor cells (Fig. 3d). Platelet counts in the control mice dropped $70 \%$, while $\mathrm{Pitpo}^{f l / f l} \mathrm{Pf4}-\mathrm{Cr} \mathrm{C}^{+}$mice had relatively stable platelet counts. Histologic analyses of the lung tissue at the $3 \mathrm{~h}$ time point after tumor cell injection revealed that Pitpo ${ }^{f l / f l} \mathrm{Pf} 4-\mathrm{Cr} e^{+}$mice have significantly fewer (Fig. 3e, f) and smaller (Fig. 3g) thrombi in their lungs and pulmonary vasculature than those found in the control mice. These data suggest that the formation of thrombi mediated by platelet PITP $\alpha$ contributes to the thrombocytopenia induced by the tumor cells.

Previous studies have supported the hypothesis that a direct in vivo interaction (adhesion) between platelets and tumor cells can facilitate the implantation of the metastasis and promote tumor cell invasion and propagation ${ }^{33,34}$. To determine whether PITP $\alpha$ facilitates platelet interactions with B16F10 tumor cells, we characterized the pulmonary thrombi in more detail by immunohistochemical staining at $3 \mathrm{~h}$ after tumor injection. We observed that at the core of these thrombi, there were a small number of tumor cells that were enveloped by platelets. This shroud of platelet-rich thrombi was much larger in the control mice than that found in the Pitpo ${ }^{f l / f l} \mathrm{Pf} 4-\mathrm{Cre}^{+}$mice (Fig. $3 \mathrm{~g}$ ). Correspondingly, PITP $\alpha$-null platelets have significantly reduced ex vivo adhesion to tissue-cultured tumor cells than PITP $\alpha$ wild-type platelets (Fig. 3 h). Together, these findings suggest that PITP $\alpha$ in platelets promotes platelet-tumor interaction and platelet-rich thrombi around tumors.

Tumor-induced thrombin and fibrin generation requires PITP $\alpha$. Since hemostatic plugs are often composed of aggregated platelets that are woven together by fibrin, we analyzed the tumor-induced thrombi for fibrin by immunohistochemistry. We observed that the area of fibrin staining was about six-fold higher in the lung tissues of the control mice when compared to the Pitpo ${ }^{f l / f l}$ Pf4-Cre ${ }^{+}$mice (Fig. $4 \mathrm{a}, \mathrm{b}$ ).
Platelets support fibrin formation by providing a negatively charged surface for the prothrombinase components (FVa and $\mathrm{FXa}$ ) to assemble and activate thrombin. This occurs once a

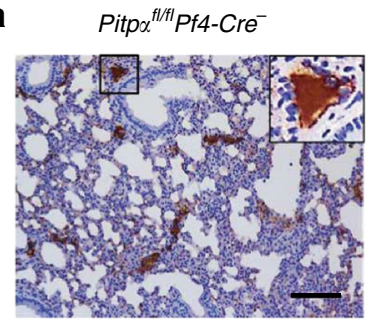

b

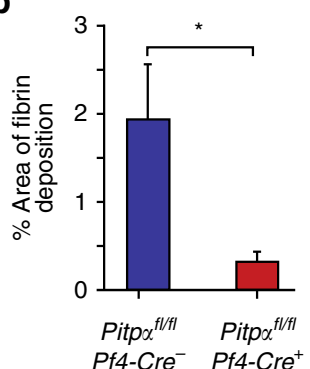

d

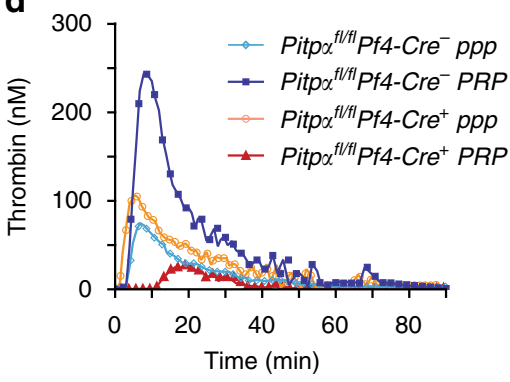

$\mathbf{f}$

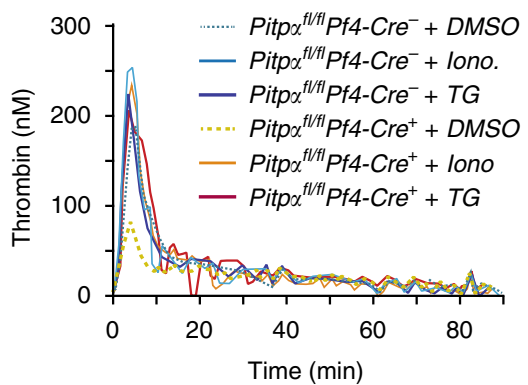

Pitp $\alpha^{f l / f l}$ Pf4-Cre ${ }^{+}$

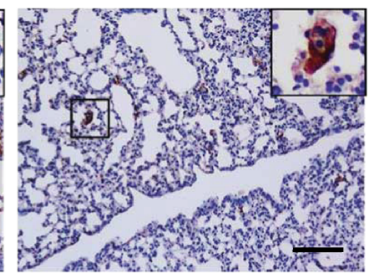

C

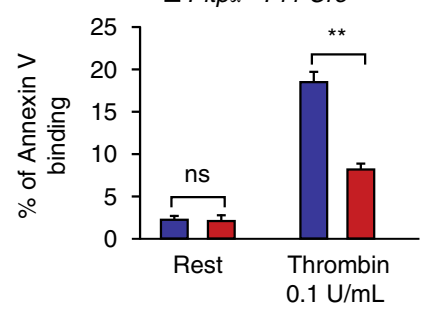

e

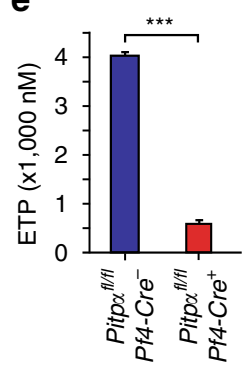

g $\square$ Pitp $\alpha^{f l / f l} P f 4-C r e^{-}$ $\square$ Pitp $\alpha^{f / f l} P f 4-C r e^{+}$

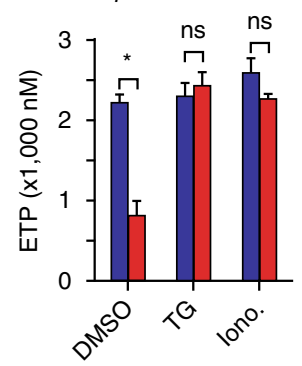

Fig. 4 Loss of PITP $\alpha$ in platelets impairs fibrin deposition and thrombin generation. a Immunohistochemistry staining for fibrin in tumor-induced thrombi found in lung tissue at $3 \mathrm{~h}$ after tumor injection. The brown color indicates fibrin deposition within the tissue. Black scale bars represent 100 $\mu \mathrm{m}$. b Quantification of fibrin deposition based on immunohistochemistry staining. $N=3$ mice per group. ${ }^{\star} p<0.05$, unpaired Student's $t$-test. Error bars are s.d. c Platelets lacking PITP $\alpha$ have an impaired ability to bind Annexin $V$ ex vivo. The mean values are averaged from four independent experiments. ${ }^{\star \star} p=0.001$, unpaired Student's $t$-test. Error bars are s.d. d Ex vivo TGA initiated by B16F10 tumor cells. Shown is representative kinetics of thrombin generation in PRP and in PPP. e The endogenous thrombin potential (ETP) shown is the mean value of total thrombin generated in PRP, containing either PITP $\alpha$ wild-type platelets (blue bar) or PITP $\alpha$-null platelets (red bar). $N=3$ mice per group. ${ }^{\star \star} p=0.01$, unpaired Student's $t$-test. Error bars are s.d. f, $\mathbf{g}$ Thrombin generation initiated by B16F10 tumor cells in the presence of agonist TG and calcium ionophore (lono.). $N=3$ mice per group. ${ }^{\star} p<0.05$, unpaired Student's $t$-test. Error bars are s.d 
a

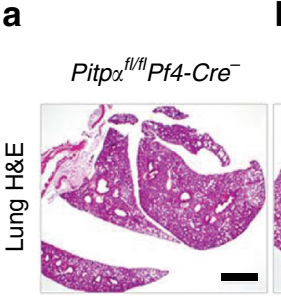

b
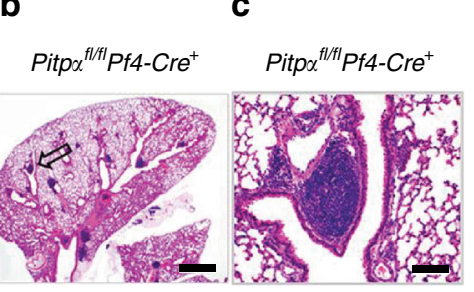

e

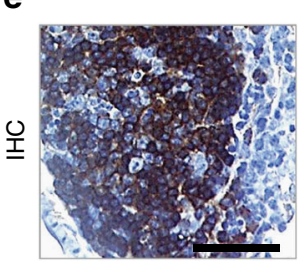

CD45R f

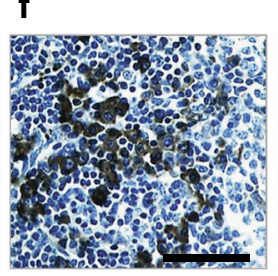

CD3 g

g

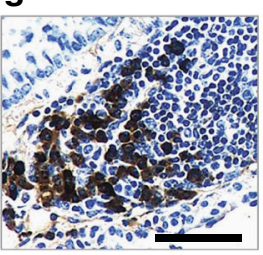

Ly-6G/C

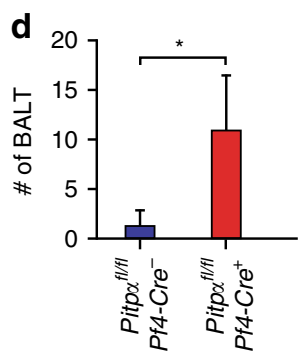

h

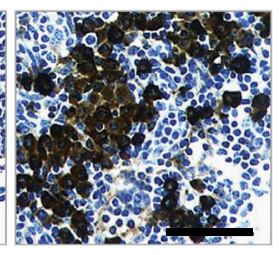

NKp46

Fig. 5 Loss of PITP $\alpha$ in platelets leads to a mucosal immune response. a-c Lung tissues were harvested $48 \mathrm{~h}$ after tumor injection and stained with H\&E. Pitpo ${ }^{f / / f l} P f 4-C_{r}{ }^{+}$mice lacking PITP $\alpha$ in their platelets (b) demonstrate prominent formation of BALT (bronchus-associated lymphoid tissue or BALT hyperplasia), such as the one indicated by the arrow. This response was rarely observed in the control mice (a). A higher magnification of a typical BALT hyperplasia is shown in $\mathbf{c}$. The black scale bars indicate $200 \mu \mathrm{m}$ for $\mathbf{a}, \mathbf{b}$, and $50 \mu \mathrm{m}$ for $\mathbf{c}$. d Average number of BALT hyperplasia per section across 300 $\mu \mathrm{m}\left(n=3\right.$ mice per group, ${ }^{\star} p<0.05$, unpaired Student's $t$-test. Error bars are s.d.). e-h Immunohistochemistry staining of hyperplasia in Pitp ${ }^{f / / f l} P f 4-C r e^{+}$ mice for major leukocyte makers as indicated. Black scale bars represent $200 \mu \mathrm{m}$

platelets flip the negatively charged phospholipid phosphatidylserine from the inner leaflet of their cell membrane to the outer leaflet. Using the Annexin V-binding assay to detect phosphatidylserine exposure on the outer membrane leaflet of platelets, we observed that Annexin V-binding was significantly reduced in PITP $\alpha$-null platelets after activation by agonists (thrombin at 0.1 $\mathrm{U} / \mathrm{ml}$ and collagen at $5 \mu \mathrm{g} / \mathrm{ml}$ ) when compared to the control platelets (Fig. 4c). This indicates that PITP $\alpha$-null platelets have an impaired ability to externalize negatively charged lipids on their surface, which in turn cause defects in prothrombinase complex assembly, prothrombin activation, and ultimately fibrin generation.

B16F10 melanoma cells have been shown to express high levels of tissue factor on their surface, thereby allowing these tumor cells to initiate the coagulation cascade ${ }^{35}$. To analyze the contribution of platelet PITP $\alpha$ to B16F10 melanoma cell-induced prothrombin activation, we utilized a well-described fluorometric thrombin generation assay (TGA) to investigate the impact of platelet PITP $\alpha$ on thrombin generation in platelet-rich plasma (PRP). When tumor cells were added to PRP that was derived from the Pitpo ${ }^{f l / f l} P f 4-\mathrm{Cre}^{+}$mice, we observed $80 \%$ less thrombin generation when compared to PRP derived from the controls (Fig. 4d, e). This effect was platelet-dependent, since thrombin generation in platelet poor plasma (PPP) was identical between the two genotypes. We also analyzed the ability of Pitpo ${ }^{f l / f l} P f 4-C r e^{+}$ mouse-derived PRP to support thrombin generation when stimulated by standard tissue factors, and we found similar, albeit smaller, defects (Supplementary Fig. 6). A peculiar finding is that thrombin generation is further suppressed in PRP from Pitpo ${ }^{f l / f l}$ Pf4-Cre ${ }^{+}$mice in comparison to that seen in PPP (Fig. 4d). Although the explanation for this observation is unclear, it suggests that platelets lacking PITP $\alpha$ suppress the ability of tumor cell tissue factor to initiate coagulation.

Under normal circumstances, generation of $\mathrm{IP}_{3}$ within platelets stimulates a rise in cytoplasmic calcium, which in turn exposes phosphatidylserine on the surface of platelets to support thrombin generation. We hypothesized that the defect in thrombin generation found in Pitpo ${ }^{f l / f l} \mathrm{Pf4}-\mathrm{Cr} e^{+}$plasma was due to impaired $\mathrm{IP}_{3}$ production, as shown previously, which caused low cytoplasmic calcium concentrations. To test this hypothesis, we artificially raised the intracellular calcium concentration and analyzed thrombin generation in PRP. We used ionophore A23187, which transports extracellular calcium into the platelet cytoplasm, as well as thapsigargin (TG), which can mobilize intracellular calcium by an $\mathrm{IP}_{3}$-independent mechanism ${ }^{36,37}$. Both reagents have been demonstrated to activate platelets by increasing cytoplasmic free calcium levels ${ }^{38-40}$. Both Pitpo ${ }^{f l / f l} P f 4$ $\mathrm{Cre}^{+}$and Pitpo $e^{f / f l}$ Pf4-Cre $e^{-}$PRP generated a similar level of thrombin in the presence of the ionophore $(10 \mu \mathrm{M})$ or TG $(2 \mu \mathrm{M})$ (Fig. 4f, g). This demonstrates that increasing the intracellular calcium completely reverts the thrombin generation defect induced by the loss of PITP $\alpha$. Thus, PITP $\alpha$ within platelets contributes to tumor metastasis through a signaling pathway that involves $\mathrm{IP}_{3}$ formation, calcium influx, phosphatidylserine externalization, and thrombin generation. Together, these data demonstrate that platelet PITP $\alpha$ is required for tumor-induced thrombin generation in vitro and thrombus formation in vivo.

Platelet PITP $\alpha$ impairs the development of bronchusassociated lymphoid tissue (BALT) hyperplasia. Although Pitpo oflfl $P f 4-C r e^{+}$mice developed less platelet-tumor adhesions than control mice during the first few hours after tumor injection (Fig. $3 \mathrm{e}-\mathrm{g}$ ), these results were not sufficient to explain the longterm effect of platelet PITP $\alpha$ on metastasis formation. To address this issue, we analyzed the histology of tumor metastasis over time. Two days after injection of the tumor cells, Pitpo ${ }^{\text {fl/fl }} P f 4-C r e^{+}$ mice developed strikingly hyperplastic BALT, a reaction that was essentially absent in the controls (Fig. 5a-d). This hyperplasia primarily consisted of hematopoietic-derived $\mathrm{CD}_{45 \mathrm{R}^{+}}$cells, including $\mathrm{T}$ cells $\left(\mathrm{CD}^{+}\right)$, neutrophils $\left(\mathrm{Ly}-6 \mathrm{G} / \mathrm{C}^{+}\right)$, and natural killer cells $\left(\mathrm{NKp} 46^{+}\right)$(Fig. 5e-h). Thus, the initial stages of tumor implantation in mice lacking platelet PITP $\alpha$ are associated with inflammatory reactions that involve multiple types of leukocytes. These data suggest that signals generated by PITP $\alpha$ in platelets protect tumor cells from immune-mediated cytotoxicity, and thereby enable tumor cell survival and propagation in both the vasculature and in the tissues. 
a

C

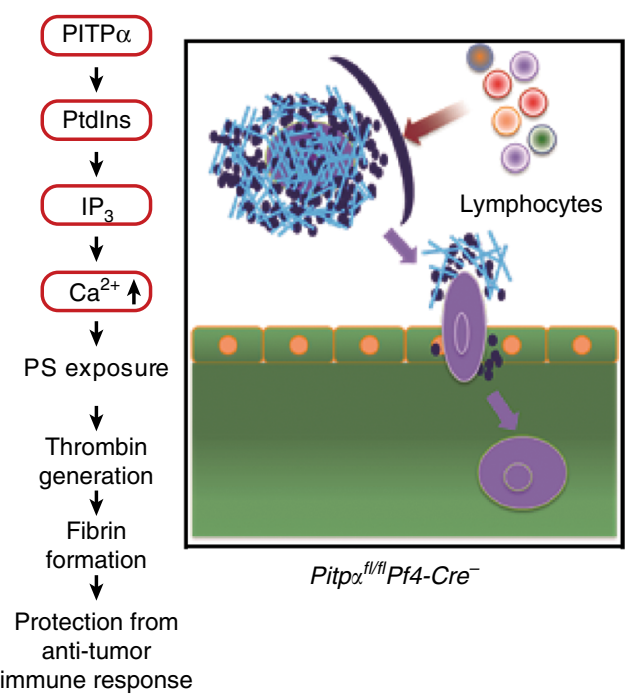

immune response b
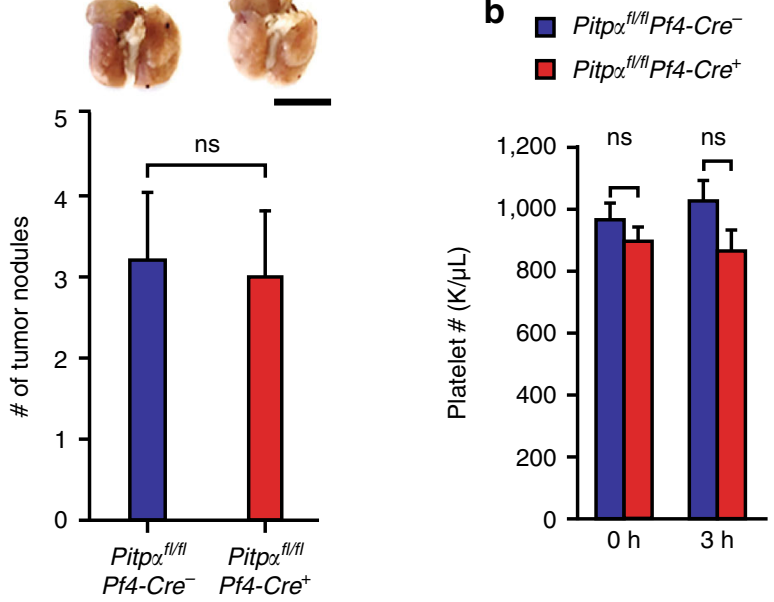

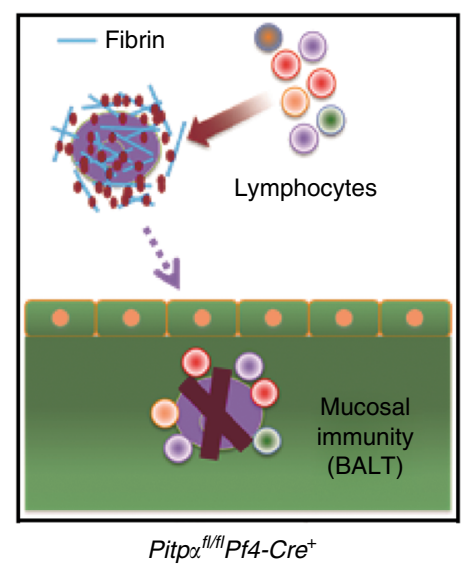

Pitpo $^{\text {flth }}$ Pf4-Cre ${ }^{+}$

Fig. 6 Coagulation inhibitor NAPc2 inhibits lung tumor metastasis in control mice. a Co-injection of tumors with coagulation factor VIla inhibitor (NAPc2) reduced lung tumor metastasis in both groups checked 2 weeks after tumor injection ( $n=10$ per group). Scale bar $=1 \mathrm{~mm}$. b Platelet counts at $3 \mathrm{~h}$ after injection of tumor cells together with coagulation factor VIla inhibitor NAPc2 ( $n=5$ of each group). Shown are the means \pm s.d. for $\mathbf{a}, \mathbf{b}$, and all statistical analysis was performed using an unpaired Student's $t$-test. c A model of the sequential events that lead to protection of tumor cells from the immune system. Normal platelets rapidly adhere to the surface of tumor cells. This interaction facilitates prothrombinase assembly on the cell surface, thrombin formation, and the deposition of fibrin. This forms a shroud that protects the tumor from lymphocyte-mediated cytotoxicity. The platelets that coat the tumor cells also facilitate the adhesion and invasion involved in metastasis. However, platelets lacking PITP $\alpha$ adhere poorly to tumor cells, fail to stimulate thrombin generation, and reduce fibrin deposition. This allows the tumor cells to be vulnerable to lymphocyte-mediated cytotoxicity (such as BALT)

Anticoagulation limits metastasis in Pitpo $^{f l / f l} \mathbf{P f 4}-\mathrm{Cre}^{-}$mice. Tissue factor-initiated coagulation has been demonstrated to protect circulating tumor cells from elimination by immune surveillance, which facilitates tumor metastasis, and B16F10 melanoma cells express high levels of tissue factor ${ }^{35}$. To understand whether tumor cell-induced thrombin generation and fibrin formation mediated by PITP $\alpha$ in platelets contribute to metastasis, we investigated the effects of a coagulation FVIIa inhibitor, nematode anticoagulant protein c2 (NAPc2) ${ }^{41}$ injection on the lung metastasis formation of B16F10 melanoma cells in vivo. NAPc2 treatment in vivo inhibited lung metastasis when analyzed 2 weeks after injection in both genotypes. Anticoagulation reduced metastasis formation and thrombocytopenia in both genotypes (Fig. 6a, b). Furthermore, the effect of the PITP $\alpha$ mutation in platelets was completely reverted by anticoagulation. Histological analyses on lung tissue sections showed no significant thrombi formation at $3 \mathrm{~h}$ after injection, and no BALT hyperplasia developed $48 \mathrm{~h}$ after injection (Supplementary Fig. 7). Together, these data suggest that tumor-initiated coagulation contributes to tumor metastasis in normal mice, and that this effect can be impaired by either anticoagulation or by the PITP $\alpha$ mutation in platelets.

To confirm that the hemostatic process mediated by PITP $\alpha$ in platelets contributes to the lung metastasis of intravenous injected B16F10 melanoma cells, we investigated the impact of platelet PITP $\alpha$ on the growth of tumor cells injected subcutaneously into the flanks of mice. The data show that the flank tumors that developed in Pitpo ${ }^{f l f l} P f 4-C r e^{+}$mice are similar to those that developed in the control mice (Supplementary Fig. 8), demonstrating that tumor cells grow at equivalent rates within the two groups. Stated alternatively, since this model does not depend on coagulation or mucosal immunity, there is no influence on tumor formation by the loss of PITP $\alpha$ in platelets.

\section{Discussion}

Clinical observations and experimental animal models have demonstrated that platelets support tumor metastasis formation. 
Our work confirms these findings and expands on these previous studies by establishing three additional and surprising observations: (1) Loss of PITP $\alpha$ in platelets causes only a partial deficit in phosphoinositide synthesis, yet it results in a major defect in second messenger formation; (2) In spite of a major biochemical defect in PITP $\alpha$-null platelets, there is no obvious hemostatic defect; and (3) The loss of PITP $\alpha$ in platelets leads to a defect in tumor-induced thrombi formation that affects anti-tumor immunity. The data shown in this study demonstrate that PITP $\alpha$-mediated phospholipid signaling in platelets contributes to lung metastasis of intravenous injected tumor cells, but has no significant impact on hemostasis. Together, this demonstrates that signaling pathways in platelets that are important for hemostasis can be distinct from those pathways involved in nonhemostatic functions.

Our data demonstrates that the loss of PITP $\alpha$ leads to the moderate loss of PtdIns $(4,5) \mathrm{P}_{2}$, but curiously leads to a far greater loss of its product, $\mathrm{IP}_{3}$. This suggests that PITP $\alpha$ is generating a particular pool of PtdIns $(4,5) \mathrm{P}_{2}$ that is critical for the formation

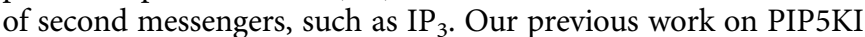
(the enzyme required for the final step of $\operatorname{PtdIns}(4,5) \mathrm{P}_{2}$ synthesis) demonstrated that second messengers, including $\mathrm{IP}_{3}$, are generated exclusively from a pool of recently synthesized PtdIns $(4,5)$ $\mathrm{P}_{2}{ }^{14}$. Together, these data show that in order to make second messengers, platelets require a cooperative effect between PITP $\alpha$ and PIP5KI to rapidly synthesize $\operatorname{PtdIns}(4,5) \mathrm{P}_{2}$ in discrete microdomains.

Since PITP $\alpha$ is required to generate normal amounts of phosphoinositides and second messengers within platelets, we anticipated finding defects in platelet-mediated hemostasis. However, we were surprised to see that the substantial amount of phosphoinositide synthesis mediated by PITP $\alpha$ does not contribute to pathways required for in vivo or ex vivo hemostasis. Our previous work has demonstrated that the loss of specific pools of PtdIns $(4,5) \mathrm{P}_{2}$ produced by PIP5KI within microdomains of platelets led to discrete platelet defects. Similarly, we speculate that microdomains of PtdIns $(4,5) \mathrm{P}_{2}$ production, that are regulated by PITP $\alpha$, are tightly coupled to calcium levels in proximity to PS scramblases. In this scenario, the loss of PITP $\alpha$ would only diminish the pool of phosphoinositides required for PS exposure, and with the remaining pools of phosphoinositides, calcium and PS exposure would be sufficient for normal hemostatic function. Alternatively stated, we hypothesize that PITP $\alpha$ contributes to the synthesis of discrete pools of phosphoinositides within specific microdomains in platelets, and these pools are not required for hemostasis.

We observed that platelets lacking PITP $\alpha$ do not efficiently adhere to tumor cells in vivo and ex vivo by a mechanism that is related to a deficiency in thrombin generation and fibrin formation. As shown in model (Fig. 6c), PITP $\alpha$-null platelets cannot form platelet-fibrin complexes that usually envelope tumor cells. This prevents thrombocytopenia in Pitpo ${ }^{f l f l}$ Pf4-Cre $e^{+}$mice following tumor cell injection. Without the platelet-fibrin shroud surrounding the tumors, these malignant cells are more vulnerable to mucosal immune responses that block tumor cell implantation. The evidence shown in this study demonstrates that impaired $\mathrm{IP}_{3}$-induced calcium release is the critical mechanism that prevents metastasis in Pitpo ${ }^{\text {fl/fl }} \mathrm{Pf4}-\mathrm{Cre}^{+}$mice. Influx of intracellular calcium activates membrane scramblase activity and exposes phosphatidylserine on the platelet surface. This facilitates tenase and prothrombinase complexes that lead to thrombin generation and fibrin polymerization around the tumor cells. Together, these findings demonstrate that PITP $\alpha$-mediated signaling in platelets indirectly augments the early stages of tumor dissemination.

While dysfunction of PITP $\alpha$-null platelets seems to be the major contributor for decreased metastasis, it is important to note that there was a $15 \%$ decrease in platelet count for these mice. Both clinically and experimentally, this small degree of thrombocytopenia was not found to be critical for hemostasis. In addition, the data in this study demonstrate that the mild thrombocytopenia in Pitpo ollfl Pf4-Cre ${ }^{+}$mice also did not contribute to the dissemination of tumors. This is based on the observation of the pronounced acute thrombocytopenia in control mice after tumor injection that was not evident in the Pitpo fll ${ }^{f l} P_{f 4}-\mathrm{Cre}^{+}$mice (Fig. 3d). Consequently, when compared to the control mice, there were actually more platelets in the circulation of the Pitpo ${ }^{f l f l} P f 4-C r e^{+}$mice during the critical early hours after tumor injection even though the metastasis defect was occurring. Thus, the inability of the tumors to metastasize could not be due to mild basal thrombocytopenia in the Pitpo oflffl Pf4-Cre ${ }^{+}$mice, but rather due to an intrinsic defect of platelet function.

In 1865, Dr. Armand Trousseau first described the association between cancer and thrombosis ${ }^{42}$. Ironically, years later, Dr. Trousseau himself tragically succumbed to widespread thrombosis caused by his pancreatic cancer. Tumor cells are known to activate platelets, which in turn facilitates tumor implantation, adhesion, propagation, and invasion of the immune system. Our study demonstrates the vital role of platelet phosphoinositide signaling in the dissemination of cancer. Furthermore, this work also clearly distinguishes the platelet signaling processes required for hemostasis from those processes that augment metastasis formation. Additional studies will be required to determine whether targeting specific non-hemostatic platelet signaling pathways could be exploited in the development of clinical therapeutics.

\section{Methods}

Mice. Animals were maintained on standard chow and tap water. Animal procedures and experiments were approved by the Institutional Animal Care and Use Committee of the University of Pennsylvania. Pitp $\alpha$ conditional mice, Flp mice, and Pf4-Cre transgenic mice were used in this study. The genetic background of al mice used was C57BL6, and both sexes of mice were used for all experiments unless noted in the methods. The ages of mice used were between 8 and 20 weeks. To produce mice with conditional targeting of the murine Pitp $\alpha$ gene, a $10.8 \mathrm{~kb}$ genomic fragment was identified in a C57BL/6 (RPCI23: 105D24) BAC library and then cloned into the pSP72 vector (Promega). The "long homology arm" was 7.42 $\mathrm{kb}$ in length, and the "short homology arm" was $1.83 \mathrm{~kb}$ in length. The pGK-gb2 loxP/FRT Neo cassette was inserted into a region that corresponded to the $3^{\prime}$ end of exon 10, and an additional loxP site was inserted into a region that corresponded to the $5^{\prime}$ end of exon 8 . Therefore, this targeting design removed a $1.55 \mathrm{~kb}$ region of Pitp $\alpha$ genomic DNA that included exons 8,9 , and 10 . The targeting vector was confirmed by PCR, restriction analysis, and sequencing after each modification step. Additional confirmation of the final clones was performed by Southern blotting analysis.

The neomycin cassette flanked by FRT sites was removed by crossing with flippase (FLP) transgenic mice (Jackson Lab). Transgenic mice that contain Cre recombinase driven by platelet factor-4 promoter (Pf4-Cre) (obtained as a generous gift from Radek Skoda, of the University of Basel, Switzerland) were further crossed with Pitp $\alpha$ conditional mice to induce the deletion of PITP $\alpha$, specifically in platelets and in megakaryocytes.

Genomic DNA isolated from tail biopsies was used for the genotyping of the conditional alleles of the Pitp $\alpha$ gene by PCR, using forward primer (5'-GAACAAGAAACTATCCAGCAGACAGACT-3') and reverse primer (5'-CTTCCTCTGCCTTGTAATCCTGAG-3').

Antibodies and reagents. Antibodies used in this study were as follows: mouse anti-human PITP $\alpha$ (5F12) (Santa Cruz Biotechnology, sc-13569; 1:400); rabbit anti-human PITP $\beta$ (Abcam, ab83795; 1:1000); rabbit anti- $\beta$-Actin (Cell Signaling, \#4970; 1:2500); goat anti-mouse TRP1 (A-20) (Santa Cruz Biotechnology, sc-10446; 1:150); rat anti-mouse CD41 (MWReg30) (Santa Cruz Biotechnology, sc-19963; 1:50); rat Anti-CD41 F(ab)2 fragments (MWReg30) (BD Biosciences, custom order; $0.12 \mu \mathrm{g} / \mathrm{g}$ body weight); anti-P-selectin (RB40.34) (BD Bioscience, custom order; $0.2 \mu \mathrm{g} / \mathrm{g}$ body weight); rat anti-mouse neutrophils (Ly-6G/C) (Santa Cruz Biotechnology, sc-59338; 1:50); rat anti-mouse CD45R (RA3-6B2) (Santa Cruz Biotechnology, sc-19597; 1:150); rat anti-mouse CD3 (17A2) (BioLegend, 100212; 1:150); rat anti-mouse CD335 (NKp46) (BioLegend, 137603; 1:120); antimouse fibrin (clone 59D8, gift from Dr. Rodney M. Camire of Children Hospital of Philadelphia, 1:500); PE-anti-mouse/rat CD62P P-selectin (RMP-1) (BioLegend, 148305 ; 1:150); PE-labeled rat anti-mouse integrin $\alpha \operatorname{IIb} \beta 3$ antibody (JON/A) 
(Emfret Analytics, \#M023-2; 1:20); ImmPRESS reagent Anti-Rat Ig (MP-7404, Vector Laboratories); and ImmPRESS reagent anti-Goat Ig (MP-7405, Vector Laboratories)

Reagents used in this study were: Fura-2/AM (Thermo Fisher Scientific, F1221); Pluronic F-127 (Sigma, P2443); purified recombinant human PITP $\alpha$ and PITP $\beta$ proteins (a generous gift from Dr. Shamshad Cockcroft of University College London); CHRONO-LUME luciferase Luciferin (CHRONO-LOG, \#393); Thrombin (CHRONO-LOG, \#386); Collagen (Sigma, \#885-1); Inositol-1,4,5triphosphate $\left[{ }^{3} \mathrm{H}\right]$ radioreceptor assay kit (PerkinElmer Life Science, \#NEK064); and Phosphorus-32 Radionuclide, $2 \mathrm{mCi}$ (PerkinElmer Life Science, \#NEX053H002MC).

Washed platelet preparation and aggregation. Washed platelets were prepared from blood collected from the inferior vena cava of anesthetized mice in the presence of $6 \times$ acid citrate dextrose buffer (ACD, $\mathrm{pH} 4.4,85 \mathrm{mM}$ sodium citrate dihydrate, $66.6 \mathrm{mM}$ citric acid, $111 \mathrm{mM}$ dextrose $)^{14}$. All procedures were done at room temperature. PRP was separated by centrifugation of blood at $200 \times g$ for 10 min. PRP was incubated with $1 \mu \mathrm{M}$ prostaglandin E1 (PGE1) for 10 min. Platelets were isolated by centrifugation of PRP at $800 \times g$ for $10 \mathrm{~min}$ to remove PPP. The pellet was resuspended in Hepes-Tyrode buffer pH 7.4 (134 mM NaCl, $3 \mathrm{mM} \mathrm{KCl}$, $0.3 \mathrm{mM} \mathrm{NaH}_{2} \mathrm{PO}_{4}, 12 \mathrm{mM} \mathrm{NaHCO} 3,2 \mathrm{mM} \mathrm{MgCl}_{2}, 5 \mathrm{mM}$ Hepes, $5 \mathrm{mM}$ glucose, and $0.35 \% \mathrm{BSA}$ ). For the aggregation assay, washed platelets were adjusted to $2 \times$ $10^{8}$ platelets $/ \mathrm{ml}$ by using Hepes-Tyrode's buffer and supplemented with $1 \mathrm{mM}$ $\mathrm{CaCl}_{2}$. The aggregation was measured by the turbidometric method at $37^{\circ} \mathrm{C}$ in the presence of CHRONO-LUME luciferase in a Lumi-Dual aggregometer (Chrono$\log )$.

Quantitation of platelet phosphoinositides. Platelets were prepared as described above and were washed once with modified Tyrode's buffer ( $\mathrm{pH}$ 6.5) $(134 \mathrm{mM}$ $\mathrm{NaCl}, 3 \mathrm{mM} \mathrm{KCl}, 0.3 \mathrm{mM} \mathrm{NaH}_{2} \mathrm{PO}_{4}, 12 \mathrm{mM} \mathrm{NaHCO}, 2 \mathrm{mM} \mathrm{MgCl}_{2}, 1 \mathrm{mM}$ EGTA, $1 \mu \mathrm{M}$ PGE1, $5 \mathrm{mM}$ Hepes, $5 \mathrm{mM}$ glucose, and $0.35 \% \mathrm{BSA})$. The platelets were then resuspended to $1 \times 10^{9} / \mathrm{ml}$ by using modified Tyrode's buffer ( $\mathrm{pH} 7.4$ ) without PGE1, EGTA, and $\mathrm{NaH}_{2} \mathrm{PO}_{4}$. The platelets were supplemented with $1 \mathrm{mM}$ $\mathrm{CaCl}_{2}$. Platelet suspensions $(0.5 \mathrm{ml})$ were incubated (phosphate-starved) at $37^{\circ} \mathrm{C}$ for $30 \mathrm{~min}$ and then supplemented with $0.5 \mathrm{mCi}$ of ${ }^{32} \mathrm{P}$ for $90 \mathrm{~min}$. The incorporation of ${ }^{32} \mathrm{P}$ was halted by the addition of $50 \mu \mathrm{l}$ of ice-cold $\mathrm{HCl}$ and 1 volume of methanol:chloroform (1:1) on ice. Mixtures were vortexed for $1 \mathrm{~min}$ to extract total phospholipids and were centrifuged at $2000 \times g$ for $3 \mathrm{~min}$. The chloroform phase was isolated, and the remaining aqueous phase was extracted again with chloroform. The two chloroform phases were combined and evaporated under $\mathrm{N}_{2}$ flow. The dried residue was resuspended in $25 \mu \mathrm{l}$ of ice-cold chloroform:methanol (1:1). Total phospholipids in the chloroform/methanol solution were fractionated by TLC and analyzed as described ${ }^{14}$. The levels of each phosphoinositide were quantified by JustTLC software (Sweday).

Quantitation of $\mathbf{I P}_{\mathbf{3}}$ formation in platelets. The washed platelets were prepared as described above, and their density was adjusted to $7-10 \times 10^{8} / \mathrm{ml}$ in Hepes-Tyrode's buffer that was supplemented with $1 \mathrm{mM} \mathrm{CaCl}_{2}$. Platelets in $200 \mu \mathrm{l}$ aliquots were activated by thrombin at $1 \mathrm{U} / \mathrm{ml}$ for indicated times. The reaction was halted by adding $40 \mu \mathrm{l}$ of ice-cold $20 \%$ perchloric acid, and incubated for $20 \mathrm{~min}$ to lyse the cells. The cellular debris was removed by centrifugation at $2000 \times g$ for $15 \mathrm{~min}$, and the supernatant was adjusted to $\mathrm{pH} 7.5$ by the addition of $\mathrm{KOH}$, and then clarified again at $2000 \times g$ for $15 \mathrm{~min}$ at $4{ }^{\circ} \mathrm{C}$ before harvesting the final supernatant. Quantitation of $\mathrm{IP}_{3}$ was performed by using the inositol-1,4,5-trisphosphate $\left[{ }^{3} \mathrm{H}\right]$ radio-receptor assay kit (PerkinElmer), according to the manufacturer's protocol.

In vivo thrombosis tail bleeding time. The distal $5 \mathrm{~mm}$ tail segment of 5-6weeks-old mice were amputated with a scalpel after administration of anesthesia. The tails were immediately immersed in $37^{\circ} \mathrm{C}$ saline. The bleeding time was presented as the sum of bleeding within $15 \mathrm{~min}$ of observation, including rebleeding. The time of complete cessation of blood flow (i.e., no blood flow for 1 min) was noted. The lost blood was collected in PBS and the blood cells were lysed in Red Blood Cell Lysing buffer (Sigma-Aldrich, R7757) to collect protein lysate. The blood volume was represented by the measurement of hemoglobin in the lysate of lost red blood cells ${ }^{43}$.

$\mathrm{FeCl}_{3}$-induced carotid thrombosis formation. Mice were anesthetized using $2 \%$ isoflurane gas in oxygen. A midline incision was made in the neck, and the right carotid artery was exposed by blunt dissection. Whatman filter paper $\left(\# 1,1 \mathrm{~mm}^{2}\right)$ soaked in $7.5 \% \mathrm{FeCl}_{3}$ was applied to the exposed artery for $2 \mathrm{~min}$. After removal of the filter paper, the artery was washed with PBS, and blood flow was recorded using a small animal blood flow meter (model T106, Transonic Systems Inc., Ithaca, NY) for $30 \mathrm{~min}$. The time to full occlusion is reported.

Laser-induced in vivo thrombosis. Male mice 8-12 weeks of age were anesthetized via intraperitoneal injection of sodium pentobarbital $(90 \mathrm{mg} / \mathrm{kg})^{30}$. A cannula was introduced into the jugular vein for the delivery of antibodies and additional anesthetic as needed. The cremaster muscle was exteriorized, cleaned of connective tissue, opened, and spread flat on the glass coverslip of a custom-built chamber for viewing by intravital microscopy. The cremaster preparation was continuously superfused with bicarbonate buffer warmed to $36.5^{\circ} \mathrm{C}$ and bubbled with $95 \% \mathrm{~N}_{2} /$ $5 \% \mathrm{CO}_{2}$. The cremaster microcirculation was visualized using an Olympus BX61WI upright microscope with a $60 \times(0.9 \mathrm{NA})$ water immersion objective, coupled to a Yokogawa CSU-X1 spinning disk confocal scanner. Laser injury was induced with a pulsed nitrogen dye laser (SRS NL100, $440 \mathrm{~nm}, 55-65 \%$ power setting) focused on the vessel wall by the microscope objective. The laser fired at the vessel wall until only a small number of red blood cells exited the lumen of the vessel (1-10 laser pulses). Confocal fluorescence images were acquired using a CoolSnap HQ CCD digital camera (Photometrics, Tucson, AZ). The microscope, confocal scanner, lasers, and camera were all controlled and synchronized using Slidebook 5.0 image acquisition and analysis software (Intelligent Imaging Innovations). Arterioles (30-40 $\mu \mathrm{m}$ diameter) with unperturbed blood flow were selected for study. Anti-CD41 F(ab)2 fragments $(0.12 \mu \mathrm{g} / \mathrm{g}$ body weight; clone MWReg30, BD Bioscience) and anti-P-selectin $(0.2 \mu \mathrm{g} / \mathrm{g}$ body weight; clone RB40.34, BD Bioscience) antibodies were labeled with Alexa fluor dye monoclonal antibody labeling kits (Alexa-488, Alexa-568, and Alexa-647), according to the manufacturer's instructions (Invitrogen).

\section{Quantitative analysis of the lung metastasis of B16F10 melanomas. The} B16F10 cell line was obtained from the American Type Culture Collection (Manassas, VA, USA) and cultured in Dulbecco's Modified Eagle's Medium that was supplemented with $10 \% \mathrm{v} / \mathrm{v}$, fetal calf serum, and $300 \mu \mathrm{g} / \mathrm{ml} \mathrm{L}$-glutamine. Tumor cells from a mid-log phase culture were collected by brief exposure to $0.05 \%$ trypsin/EDTA solution (Invitrogen), washed twice with PBS, and then resuspended in PBS at a density of $5 \times 10^{6} / \mathrm{ml}$. A $200 \mu \mathrm{l}$ aliquot of B16F10 tumor cells $\left(1 \times 10^{5}\right.$ cells $)$ with or without FVIIa inhibitor NAPc2 $(150 \mathrm{nM})$ was injected through the tail veins of the mice. At various time intervals after injection, the mice were euthanized, and perfused with $10 \mathrm{ml}$ ice-cold PBS that was supplemented with $4 \%$ formalin. The lungs were carefully removed, dissected free of other connective tissues, and then fixed in $10 \%$ formalin. The tumor nodules on the lung surface were counted under microscopy, and the lung was weighed.

Quantification of thrombus formation. Tumor injection-induced thrombi formations in lung tissue were quantified on paraffin-embedded tissue sections. Three slides across $300 \mu \mathrm{m}$ were collected in each sample at $100 \mu \mathrm{m}$ intervals. Platelet-rich thrombi were identified by immunohistochemistry staining of CD41, and the numbers either in the vasculature or within the pulmonary tissue were counted under the microscope at $10 \times$ magnification from three randomly selected optical fields.

Immunohistochemistry. The slides were de-paraffinized with xylene, dehydrated in ethanol, and then treated with $20 \mu \mathrm{g} / \mathrm{ml}$ proteinase $\mathrm{K}$ in TE buffer, $\mathrm{pH} 8.0$ containing $0.5 \%$ triton $\mathrm{X}-100$ for $15 \mathrm{~min}$ at $37^{\circ} \mathrm{C}$. The slides were then treated with $3 \% \mathrm{H}_{2} \mathrm{O}_{2}$ for 15 min to block endogenous peroxidase, and then treated with $2.5 \%$ normal serum for $60 \mathrm{~min}$ to block non-specific antibody binding. The tissue sections were stained with primary antibodies and peroxidase secondary antibody as instructed by the ImmPRESS reagent kit (Vector Laboratories). The signals were visualized by developing with $\mathrm{DAB}$ as indicated by the ImmPact DAB peroxidase substrate kit (Vector Laboratories).

Immunoblotting. Washed platelets were prepared as described above. After final centrifugation, the platelet pellet was resuspended in ice-cold RIPA buffer (SigmaAldrich, R0278) supplemented with cOmplete protease inhibitor (Roche,

$11836170001)$ to lyse the platelets. Platelet lysate protein concentration was measured with BCA kit (Thermo Scientific Pierce, 23225) and adjusted with RIPA buffer so that each sample had a total of $50 \mu \mathrm{g}$ of protein. NuPage LDS Sample buffer (Invitrogen, NP0008) and NuPage reducing agent (Invitrogen, NP0004) were added to each sample aliquot. Samples were loaded on a NuPage $4-12 \%$ BisTris protein gel (Invitrogen, NP0321) and run in reducing conditions with a NuPage MOPS SDS running buffer (Invitrogen, NP0001). Gels were then blotted onto polyvinylidene fluoride membrane (Invitrogen, LC2002). After blotting, membranes were blocked with 5\% Blotting Grade Blocker Non-Fat Dry Milk (BioRad \#1706404XTU) in 0.1\% Tween/TBS (BioRad \#1706435, \#1662404) for $1 \mathrm{~h}$. Blots were incubated with primary antibody in blocking buffer overnight at $4{ }^{\circ} \mathrm{C}$. Afterwards, blots were incubated with secondary antibody conjugated with HRP (anti-rabbit or anti-mouse; Cell Signaling Technology, \#7074, \#7076) for $1 \mathrm{~h}$ at room temperature. Blots were washed several times with $0.1 \%$ Tween/TBS between each step. Blots were developed with ECL Prime Western Blotting detection reagent (GE Healthcare Life Sciences, RPN2232), exposed on autoradiographic film (Denville Scientific, E3018), and digitized on a scanner. Uncropped immunoblots are shown in Supplementary Fig. 9.

Annexin $\mathbf{V}$ binding on agonist-activated platelets. The binding of Annexin $\mathrm{V}$ on platelets was quantified by flow cytometry ${ }^{44}$. Whole blood was collected from the inferior vena cava and diluted at 1:100 in the final resuspension buffer $(\mathrm{pH} 7.4,134$ $\mathrm{mM} \mathrm{NaCl}, 3 \mathrm{mM} \mathrm{KCl}, 0.3 \mathrm{mM} \mathrm{NaH}_{2} \mathrm{PO}_{4}, 12 \mathrm{mM} \mathrm{NaHCO}, 2 \mathrm{mM} \mathrm{MgCl}, 5 \mathrm{mM}$ Hepes, $5 \mathrm{mM}$ glucose, and $0.35 \% \mathrm{BSA}$ ) that contained $2 \mathrm{mM} \mathrm{CaCl}_{2}$. GPRP (Sigma, 
Cat\# G1895-25mg) at a final concentration of $1 \mathrm{mM}$ was supplemented to prevent fibrin polymerization before the stimulation of agonists. Diluted platelets in whole blood were stimulated with an agonist combination that contained $5 \mu \mathrm{g} / \mathrm{ml}$ collagen and $0.1 \mathrm{U} / \mathrm{ml}$ thrombin at $37^{\circ} \mathrm{C}$ for $10 \mathrm{~min}$. The samples were then labeled with $50 \mathrm{nM}$ Annexin V-Alexa-FITC antibody (BD Biosciences, \#556420; 1:20) and CD41a-PE antibody (BD Biosciences, \#558040; 1:100) to identify platelets at room temperature for $30 \mathrm{~min}$. The binding was analyzed by flow cytometry (BD FACSCanto II Flow Cytometry System) gating on the CD41positive cell population.

Flow cytometry. After collecting platelets, as described above, cells were diluted to $10^{7} \mathrm{cells} / \mathrm{ml}$. Platelets $(100 \mu \mathrm{l})$ were stained with PE-labeled rat anti-mouse integrin $\alpha \mathrm{IIb} \beta 3$ antibody (JON/A) (Emfret Analytics, \#M023-2; 1:20) for $30 \mathrm{~min}$. The tubes were washed with $0.1 \%$ BSA in PBS and centrifuged to remove non-bound antibody and resuspended in $0.1 \%$ BSA in PBS before analyzing cells on FACSCanto II Flow Cytometry System (BD Bioscience). Flow cytometry was assisted by the Flow Cytometry Core Laboratory at Children's Hospital of Philadelphia core facility.

Thrombin generation assay. Thrombin generation in platelets was measured in the automated analyzer CEVERON alpha with a TGA module (TECHNOTHROMBIN TGA, DiaPharma) based on monitoring the formation of thrombin by means of a fluorogenic substrate upon activation of the coagulation cascade by tissue factor. Blood was withdrawn in the presence of $6 \times \mathrm{ACD}$, and PRP was collected after centrifuging at $200 \times g$ for $10 \mathrm{~min}$. The samples were further centrifuged for $15 \mathrm{~min}$ at $1500 \times g$ to collect the PPP as controls. Platelets in PRP were counted, and the concentration was adjusted to $5 \times 10^{8} / \mathrm{ml}$. For each measurement, $40 \mu \mathrm{l}$ of each sample, $10 \mu \mathrm{l}$ of TGA trigger B16F10 tumor cells $\left(1 \times 10^{7} / \mathrm{ml}\right)$, and agonists were mixed in 96 -well plates in duplicate. The samples were maintained at $33^{\circ} \mathrm{C}$. Once $50 \mu \mathrm{l}$ of TGA substrate was added into each well, measurements were obtained at $30 \mathrm{~s}$ intervals for $90 \mathrm{~min}$. Thrombin generation was calculated by the manufacturer's software utilizing a standard thrombin calibration curve that was derived separately.

Quantification of BALT hyperplasia. The BALT hyperplasia on each section was manually counted under microscope at $4 \times$ magnification after H\&E staining. One section per $100 \mu \mathrm{m}$ tissue was used for the quantification, and a total of three slides across $300 \mu \mathrm{m}$ were collected.

Platelet counts. Peripheral blood was collected through retro-orbital puncture of Pitpo $e^{f l f l} \mathrm{Pf4}-\mathrm{Cr}^{+}$and Pitpo ${ }^{f l / f l} \mathrm{Pf4}-\mathrm{Cr} e^{-}$mice matched for age and gender. Complete blood counts (CBC) and mean platelet volumes were analyzed using a Drew Hemavet Hemacytometer (HV1700).

Intracellular calcium flux measurement. PRP was collected and platelets were suspended to $5 \times 10^{8} / \mathrm{ml}$ in Tyrode's buffer without calcium. Apyrase and PGEwere added to prevent aggregation. Platelets were loaded with fura-2/AM $(5 \mu \mathrm{M})$ in the presence of Pluronic F-127 $(0.2 \mu \mathrm{g} / \mathrm{ml})$ for $15 \mathrm{~min}$ at $37^{\circ} \mathrm{C}$, then washed and resuspended in Tyrode's buffer without calcium. Stirred platelets were activated with thrombin, and fluorescence was measured with an Aminco Bowman Series 2 Luminescence spectrophotometer ${ }^{45}$. The excitation wavelengths alternated between 340 and $380 \mathrm{~nm}$, and emission was measured at $510 \mathrm{~nm}$. Each measurement was calibrated using Triton X-100 and EGTA. Fura- $2 K_{d}=224$ nM. Maximal increase in $\left[\mathrm{Ca}^{2+}\right]$ was determined by subtracting baseline before stimulus from peak.

Fibrin staining. Fibrin production in thrombi was stained by rapid microwave phosphotungstic acid hematoxylin (P.T.A.H) (American MasterTech) on $6 \mu \mathrm{m}$ paraffin-embedded sections of lung tissue. De-paraffinized slides were incubated in microwave heated $10 \%$ zinc chloride solution for $15 \mathrm{~min}$, washed in running tap water, and followed by incubation in microwave heated $5 \%$ ferric ammonium sulfate solution for $2 \mathrm{~min}$. After washing with water, the slides were further stained for $30 \mathrm{~min}$ in P.T.A.H that had been pre-heated in a microwave for $10-20 \mathrm{~s}$. The slides were dehydrated in $95 \%$ alcohol and then covered with a mounting slip prior to microscope analysis.

Lung metastatic analysis of intravenous injected LLC. LLC cell line was obtained from the American Type Culture Collection (Manassas, VA, USA, \#CRL1642) and cultured in Dulbecco's Modified Eagle's Medium that was supplemented with $10 \% \mathrm{v} / \mathrm{v}$, fetal calf serum (Sigma Aldrich), and $300 \mu \mathrm{g} / \mathrm{ml} \mathrm{L-glutamine}$ (Invitrogen). Tumor cells from a mid-log phase culture were collected by brief exposure to $0.05 \%$ trypsin/EDTA solution, washed twice with PBS, and then resuspended in PBS at a density of $5 \times 10^{6} / \mathrm{ml}$. A $200 \mu \mathrm{l}$ aliquot of tumor cells $\left(1 \times 10^{5}\right.$ cells) was injected through the tail vein of the mice. The mice were euthanized at 3 weeks after injection, and perfused with $10 \mathrm{ml}$ ice-cold PBS that was supplemented with $4 \%$ formalin. The lungs were carefully removed, dissected free of other connective tissues, and then fixed in $10 \%$ formalin. The tumor nodules on the lung surface were counted under microscopy. Some of the lungs were paraffinembedded and sectioned at $6 \mu \mathrm{m}$ for H\&E staining. The tumors on tissue sections were counted under microscope at $10 \times$ magnification across $300 \mu \mathrm{m}$ of each lung and presented as average number of tumors per section.

Flank tumors. B16F10 melanoma cells were utilized for flank tumor growth measurement. Tumor cells at $1 \times 10^{6} / \mathrm{ml}$ in PBS were subcutaneously injected. Two weeks after injection, mice were euthanized and the tumors were dissected, weighed, and fixed in $10 \%$ formalin.

Statistics. Two-tailed unpaired or paired Student's $t$-tests were applied for the comparison of two means for all analyses, except for the tail bleeding times and intravital assay, which utilized the Mann-Whitney test. $P$-values of less than 0.05 were considered statistically significant.

Data availability. All relevant data are available from the authors upon reasonable request.

Received: 8 July 2016 Accepted: 24 August 2017

Published online: 31 October 2017

\section{References}

1. Sierko, E. \& Wojtukiewicz, M. Z. Platelets and angiogenesis in malignancy. Semin. Thromb. Hemost. 30, 95-108 (2004).

2. Costantini, V., Zacharski, L. R., Moritz, T. E. \& Edwards, R. L. The platelet count in carcinoma of the lung and colon. Thromb. Haemost. 64, 501-505 (1990).

3. Ayhan, A. et al. The value of preoperative platelet count in the prediction of cervical involvement and poor prognostic variables in patients with endometrial carcinoma. Gynecol. Oncol. 103, 902-905 (2006).

4. Taucher, S. et al. Impact of pretreatment thrombocytosis on survival in primary breast cancer. Thromb. Haemost. 89, 1098-1106 (2003).

5. Brown, K. M., Domin, C., Aranha, G. V., Yong, S. \& Shoup, M. Increased preoperative platelet count is associated with decreased survival after resection for adenocarcinoma of the pancreas. Am. J. Surg. 189, 278-282 (2005).

6. Kaushansky, K. Historical review: megakaryopoiesis and thrombopoiesis. Blood 111, 981-986 (2008).

7. Boucharaba, A. et al. Platelet-derived lysophosphatidic acid supports the progression of osteolytic bone metastases in breast cancer. J. Clin. Invest. 114, 1714-1725 (2004).

8. Camerer, E. et al. Platelets, protease-activated receptors, and fibrinogen in hematogenous metastasis. Blood 104, 397-401 (2004).

9. Bakewell, S. J. et al. Platelet and osteoclast beta3 integrins are critical for bone metastasis. Proc. Natl Acad. Sci. USA 100, 14205-14210 (2003).

10. Jain, S. et al. Platelet glycoprotein Ib alpha supports experimental lung metastasis. Proc. Natl Acad. Sci. USA 104, 9024-9028 (2007).

11. Palumbo, J. S. et al. Platelets and fibrin(ogen) increase metastatic potential by impeding natural killer cell-mediated elimination of tumor cells. Blood 105, 178-185 (2005).

12. Ho-Tin-Noé, B. et al. Innate immune cells induce hemorrhage in tumors during thrombocytopenia. Am. J. Pathol. 175, 1699-1708 (2009).

13. Min, S. H. \& Abrams, C. S. Regulation of platelet plug formation by phosphoinositide metabolism. Blood 122, 1358-1365 (2013).

14. Wang, Y. et al. Loss of PIP5KIbeta demonstrates that PIP5KI isoform-specific PIP2 synthesis is required for IP3 formation. Proc. Natl Acad. Sci. USA 105, 14064-14069 (2008).

15. Wang, Y. et al. Platelets lacking PIP5KI $\gamma$ have normal integrin activation but impaired cytoskeletal-membrane integrity and adhesion. Blood 121, 2743-2752 (2013).

16. Hartwig, J. H. et al. Thrombin receptor ligation and activated Rac uncap actin filament barbed ends through phosphoinositide synthesis in permeabilized human platelets. Cell 82, 643-653 (1995)

17. Yang, S. A., Carpenter, C. L. \& Abrams, C. S. Rho and Rho-kinase mediate thrombin-induced phosphatidylinositol 4-phosphate 5-kinase trafficking in platelets. J. Biol. Chem. 279, 42331-42336 (2004).

18. De Matteis, M. A. \& Godi, A. PI-loting membrane traffic. Nat. Cell Biol. 6, 487-492 (2004)

19. Di Paolo, G. \& De Camilli, P. Phosphoinositides in cell regulation and membrane dynamics. Nature 443, 651-657 (2006).

20. Creba, J. A. et al. Rapid breakdown of phosphatidylinositol 4-phosphate and phosphatidylinositol 4,5-bisphosphate in rat hepatocytes stimulated by vasopressin and other $\mathrm{Ca}^{2+}$-mobilizing hormones. Biochem. J. 212, 733-747 (1983).

21. Krauss, M. \& Haucke, V. Phosphoinositide-metabolizing enzymes at the interface between membrane traffic and cell signaling. EMBO Rep. 8, 241-246 (2007). 
22. Alb, J. G. Jr et al. Mice lacking phosphatidylinositol transfer protein-alpha exhibit spinocerebellar degeneration, intestinal and hepatic steatosis, and hypoglycemia. J. Biol. Chem. 278, 33501-33518 (2003).

23. Jones, S. M., Alb, J. G. Jr, Phillips, S. E., Bankaitis, V. A. \& Howell, K. E. A phosphatidylinositol 3-kinase and phosphatidylinositol transfer protein act synergistically in formation of constitutive transport vesicles from the transGolgi network. J. Biol. Chem. 273, 10349-10354 (1998).

24. Giansanti, M. G. et al. The class I PITP giotto is required for Drosophila cytokinesis. Curr. Biol. 16, 195-201 (2006)

25. Xie, Y. et al. Phosphatidylinositol transfer protein-alpha in netrin-1-induced PLC signaling and neurite outgrowth. Nat. Cell Biol. 7, 1124-1132 (2005).

26. Cunningham, E., Thomas, G. M., Ball, A., Hiles, I. \& Cockcroft, S. Phosphatidylinositol transfer protein dictates the rate of inositol trisphosphate production by promoting the synthesis of PIP2. Curr. Biol. 5, 775-783 (1995).

27. Panaretou, C., Domin, J., Cockcroft, S. \& Waterfield, M. D. Characterization of p150, an adaptor protein for the human phosphatidylinositol (PtdIns) 3-kinase. Substrate presentation by phosphatidylinositol transfer protein to the p150. Ptdins 3-kinase complex. J. Biol. Chem. 272, 2477-2485 (1997).

28. Alb, J. G. Jr et al. Genetic ablation of phosphatidylinositol transfer protein function in murine embryonic stem cells. Mol. Biol. Cell 13, 739-754 (2002).

29. Tiedt, R., Schomber, T., Hao-Shen, H. \& Skoda, R. C. Pf4-Cre transgenic mice allow the generation of lineage-restricted gene knockouts for studying megakaryocyte and platelet function in vivo. Blood 109, 1503-1506 (2007).

30. Stalker, T. J. et al. Hierarchical organization in the hemostatic response and its relationship to the platelet-signaling network. Blood 121, 1875-1885 (2013).

31. Gay, L. J. \& Felding-Habermann, B. Contribution of platelets to tumor metastasis. Nat. Rev. Cancer 11, 123-134 (2011).

32. Eccles, S. A. Basic principles for the study of metastasis using animal models. Methods Mol. Med. 58, 161-171 (2001).

33. Labelle, M. \& Hynes, R. O. The initial hours of metastasis: the importance of cooperative host-tumor cell interactions during hematogenous dissemination. Cancer Discov. 2, 1091-1099 (2012).

34. Schumacher, D., Strilic, B., Sivaraj, K. K., Wettschureck, N. \& Offermanns, S. Platelet-derived nucleotides promote tumor-cell transendothelial migration and metastasis via P2Y2 receptor. Cancer Cell 24, 130-137 (2013).

35. Kirszberg, C. et al. Simultaneous tissue factor expression and phosphatidylserine exposure account for the highly procoagulant pattern of melanoma cell lines. Melanoma Res. 19, 301-308 (2009).

36. Takemura, H., Hughes, A. R., Thastrup, O. \& Putney, J. W. Jr. Activation of calcium entry by the tumor promoter thapsigargin in parotid acinar cells. Evidence that an intracellular calcium pool and not an inositol phosphate regulates calcium fluxes at the plasma membrane. J. Biol. Chem. 264, 12266-12271 (1989)

37. Jackson, T. R., Patterson, S. I., Thastrup, O. \& Hanley, M. R. A novel tumour promoter, thapsigargin, transiently increases cytoplasmic free $\mathrm{Ca}^{2+}$ without generation of inositol phosphates in NG115-401L neuronal cells. Biochem. J. 253, 81-86 (1988)

38. Dobrydneva, Y., Williams, R. L. \& Blackmore, P. F. Trans-resveratrol inhibits calcium influx in thrombin-stimulated human platelets. Br. J. Pharmacol. 128, 149-157 (1999)

39. White, J. G., Rao, G. H. \& Gerrard, J. M. Effects of the lonophore A23187 on blood platelets I. Influence on aggregation and secretion. Am. J. Pathol. 77, 135-149 (1974).
40. Gerrard, J. M., White, J. G. \& Rao, G. H. Effects of the lonophore A23187 on the blood platelets II. Influence on ultrastructure. Am. J. Pathol. 77, 151-166 (1974).

41. Stassens, P. et al. Anticoagulant repertoire of the hookworm Ancylostoma caninum. Proc. Natl Acad. Sci. USA 93, 2149-2154 (1996).

42. Trousseau A. Clinique Médicale de l'Hotel Dieu de Paris, 2nd ed, Vol. 3 (JB Baillère, 1865).

43. Liu, Y., Jennings, N. L., Dart, A. M. \& Du, X. J. Standardizing a simpler, more sensitive and accurate tail bleeding assay in mice. World J. Exp. Med. 2, 30-36 (2012).

44. Kimmelstiel, C. et al. Bivalirudin is a dual inhibitor of thrombin and collagendependent platelet activation in patients undergoing percutaneous coronary intervention. Circ. Cardiovasc. Interv. 4, 171-179 (2011).

45 Gupta, S. et al. CLP36 is a negative regulator of glycoprotein VI signaling in platelets. Circ. Res. 111, 1410-1420 (2012).

\section{Acknowledgements}

This study was supported by US Public Health Service Grants from the NIH: PO1 HL120846 and PO1 HL40387 to C.S.A.

\section{Author contributions}

L.Z., C.L.T., A.S., T.J.S., S.H.M., L.L., G.D.F., S.C., A.D., S.K., and C.S.A. designed and performed the experiments. L.Z., C.L.T., T.J.S., S.H.M., L.L., G.D.F., S.C., A.D., S.K., and C.S.A. analyzed the data. L.Z., C.L.T., A.S., T.J.S., S.H.M., and C.S.A. wrote the manuscript. L.Z., C.L.T., A.S., T.J.S., S.H.M., L.L., G.D.F., S.C., A.D., S.K., and C.S.A. reviewed and approved the manuscript.

\section{Additional information}

Supplementary Information accompanies this paper at doi:10.1038/s41467-017-01181-4.

Competing interests: The authors declare no competing financial interests.

Reprints and permission information is available online at http://npg.nature.com/ reprintsandpermissions/

Publisher's note: Springer Nature remains neutral with regard to jurisdictional claims in published maps and institutional affiliations.

Open Access This article is licensed under a Creative Commons Attribution 4.0 International License, which permits use, sharing, adaptation, distribution and reproduction in any medium or format, as long as you give appropriate credit to the original author(s) and the source, provide a link to the Creative Commons license, and indicate if changes were made. The images or other third party material in this article are included in the article's Creative Commons license, unless indicated otherwise in a credit line to the material. If material is not included in the article's Creative Commons license and your intended use is not permitted by statutory regulation or exceeds the permitted use, you will need to obtain permission directly from the copyright holder. To view a copy of this license, visit http://creativecommons.org/ licenses/by/4.0/

(C) The Author(s) 2017 